\title{
Consumo colaborativo no turismo: Um estudo quantitativo sobre o Airbnb no Brasil e em Portugal
}

\section{Colaborative consumption in tourism: A quantitative study on Airbnb in Brazil and Portugal}

\author{
Luciana Alves Rodas Vera \\ Universidade Federal da Bahia (UFBA) \\ lu.alvesvera@gmail.com \\ Marlusa de Sevilha Gosling \\ Universidade Federal de Minas Gerais (UFMG) \\ mg.ufmg@gmail.com \\ João Albino Matos da Silva \\ Universidade do Algarve (UAlg) \\ jsilva@ualg.pt
}

\begin{abstract}
Resumo
A economia compartilhada é uma atividade de peer-to-peer com base na obtenção, concessão ou compartilhamento de acesso a bens e serviços, coordenada através de serviços comunitários online. Tal fenômeno tem afetado o campo do Turismo por meio de diversas plataformas como o Airbnb. O objetivo deste artigo foi propor um modelo teórico para verificar os fatores que contribuem para a propensão de uso de plataformas de economia do compartilhamento no âmbito do turismo, especificamente o Airbnb. Para isso, foi realizado estudo quantitativo com 454 respondentes do Brasil e 446 de Portugal, utilizando análise de modelagem de equações estruturais. Os resultados principais indicaram que a Economia de Custos, a Expectativa de Desempenho, a Expectativa de Experiências Culturais Compartilhadas e de Construção de Vínculos Sociais, a Percepção de Cocriação de Valor e a Perspectiva Anti-indústria têm relação direta com a Propensão para o Uso.
\end{abstract}

Palavras-chave: Economia do compartilhamento; consume colaborativo; modelo teórico; Airbnb; Brasil; Portugal.

\begin{abstract}
The sharing economy is a peer-to-peer activity based on obtaining, granting or sharing access to goods and services, coordinated through online community services. This phenomenon has affected the field of Tourism through several platforms such as Airbnb. The objective of this article was to propose a theoretical model to verify the factors that contribute to the propensity to use sharing economy platforms in the scope of tourism, specifically Airbnb. For this, a quantitative study was carried out with 454 respondents from Brazil and 446 from Portugal, using structural equation modeling analysis. The main results indicated that the Cost Economy, the Performance Expectation, the Expectation of Shared Cultural Experiences and the Building of Social Links, the
\end{abstract}

Dos Algarves: A Multidisciplinary e-Journal, 38-2020.

ISBN 2182-5580 @ ESGHT - University of the Algarve, Portugal.

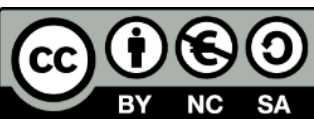

To cite this article: Vera, L. A. R., Gosling, M. S. \& da Silva, J. A. M. (2020). Consumo colaborativo no turismo: Um estudo quantitativo sobre o Airbnb no Brasil e em Portugal. Dos Algarves: A Multidisciplinary e-Journal, 38, 1-40. DOI: 10.18089/DAMeJ.2020.38.1 
Perception of Co-creation of Value and the Anti-industry Perspective are directly related to the Propensity for the Use.

Keywords: Sharing economy; collaborative consumption; theoric model; Airbnb; Brazil; Portugal.

\section{Introdução}

A economia compartilhada, também chamada de economia do compartilhamento, é um tema recente da sociedade contemporânea, em que se observa um crescimento de organizações com este perfil e da atenção de investidores às empresas que surgem nesse segmento. No contexto do turismo e da hospitalidade, percebe-se a força dessas novas empresas pela sua alta taxa de crescimento e pelo impacto na indústria do turismo.

Silveira, Petrini e Santos (2016) realizaram um estudo bibliométrico das publicações científicas internacionais relacionadas com as temáticas da economia compartilhada e do consumo colaborativo e o resultado da análise das autoras mostrou que as pesquisas que envolvem essa temática são relativamente recentes, já que apenas a partir de 2012 foi identificado um contínuo e crescente número de publicações anuais sobre o assunto. Os periódicos internacionais que mais publicaram trabalhos sobre a economia compartilhada foram: Information, Communication \& Society ( 3 artigos), Journal of Consumer Behaviour (2), Organization \& Environment (2), Journal of Cleaner Production (2), Ecological Economics (2), Law and Contemporary Problems (2), Business \& Information Systems Engineering (2) e Journal of Consumer Research (2) (Silveira et al., 2016).

O fato de se tratar de um fenômeno relativamente recente e de a academia ter despertado um interesse ainda tímido pela temática, indica oportunidades para o estabelecimento de um referencial teórico mais robusto a respeito da economia compartilhada, principalmente na área de turismo. O presente estudo teve como objetivo principal propor um modelo teórico para verificar os fatores que contribuem para a propensão de uso de plataformas de economia do compartilhamento no âmbito do turismo. Para isso, escolheu-se o Airbnb como lócus da investigação. No intuito de atingir tal objetivo, foi realizado um estudo de abordagem quantitativa, com aplicação de questionários com consumidores do Brasil e de Portugal, e análise de modelagem de equações estruturais. A amostra foi voltada apenas para os hóspedes e não para as pessoas que hospedam.

O artigo foi estruturado da seguinte forma: primeiro, o referencial teórico tratou sobre a economia compartilhada no turismo, o Airbnb e as hipóteses do estudo baseadas na literatura, e posteriormente, foram apresentados os procedimentos metodológicos, depois, a análise dos resultados e, por fim, as considerações finais.

\section{Referencial teórico}

\subsection{Economia compartilhada no turismo}

Hamari, Sjöklint e Ukkonen (2016) conceituam a economia compartilhada como uma atividade de peer-to-peer com base na obtenção, concessão ou compartilhamento de acesso a bens e serviços, coordenada através de serviços comunitários online. Já Habibi, Davidson e Laroche (2017) definem a economia do compartilhamento como um termo abrangente para 
nomear uma ampla variedade de formas de consumo baseadas na não propriedade tais como o escambo, o compartilhamento e o aluguel. Nesta direção, outros autores oferecem outros termos e nomenclaturas para refletir sobre o fenômeno.

Botsman e Rogers (2011), por exemplo, cunharam o termo consumo colaborativo para conceituar compartilhamento tradicional, escambo, empréstimo, negociação, locação, doação e troca, reconfigurados por meio da tecnologia e comunidades entre pares. Belk (2014), por sua vez, critica o conceito de consumo colaborativo trazido por Botsman e Rogers (2011) por pensar que o termo trazido pelos autores é muito amplo. Belk (2014) propõe duas conceituações oriundas do comportamento do consumidor no contexto da economia compartilhada: o compartilhamento e o consumo colaborativo.

O autor define o compartilhamento como o ato e o processo de distribuir o que é nosso para os outros, para o uso deles, e/ou o ato e o processo de receber ou levar algo dos outros para nosso uso. O consumo colaborativo é conceituado por Belk (2014) como eventos coordenados entre os consumidores para a aquisição e distribuição de um recurso, a partir de uma taxa ou outra forma de remuneração como, por exemplo, escambo, comércio e trocas que envolvam a compensação não-monetária (Belk, 2014). A diferença entre os dois conceitos, para o autor, estaria, portanto, no fato de o consumo colaborativo envolver taxa ou outra forma de remuneração e de o compartilhamento não envolver taxa. Vera e Gosling (2017) exemplificam os conceitos de Belk (2014) no contexto do turismo ao apontar o CouchSurfing como um exemplo de plataforma que estimula o compartilhamento; e o Airbnb como um exemplo de plataforma que estimula o consumo colaborativo.

Para Souza e Lemos (2016), a economia do compartilhamento está baseada no uso de tecnologia da informação em prol da otimização do uso de recursos através de sua redistribuição, compartilhamento e aproveitamento de suas capacidades excedentes. Os autores exemplificam isso ao mencionarem que empresas emblemáticas da economia compartilhada, como Uber e Airbnb, "respectivamente ao viabilizar locomoção e acomodação nas cidades, não possuem frotas de carros ou quartos para hospedagem próprios, atuando ambas as empresas como intermediários entre os pólos interessados" (Souza \& Lemos, 2016: 1759).

O turismo é uma das áreas mais afetadas pela economia compartilhada pelo fato de os residentes locais compartilharem com os turistas casas, carros, passeios e comida (Heo, 2016). Heo (2016) acredita que a economia compartilhada tem embaralhado as fronteiras entre os consumidores e os prestadores de serviços, bem como os residentes locais e as entidades de negócios no destino turístico. Os hotéis e os taxistas podem ter uma tendência a enxergar o Airbnb e o Uber como uma concorrência desleal e acreditar que eles estão sonegando impostos e sem regulamentação. Para Heo (2016), os modelos de economia compartilhada podem ainda estar na sua infância e, por conseguinte, seus serviços podem ter, na visão de empresas locais de turismo, impactos negativos, ocasionando conflitos entre diferentes atores do campo do turismo. Nesse sentido, tal questão precisa ser estudada pela academia para torná-la mais clara.

O Airbnb é uma das plataformas mais emblemáticas da economia compartilhada no contexto do turismo. Somente no ano de 2014, ele serviu 18 milhões de hóspedes no mundo 
e obteve 75 milhões de diárias (Tussyadiah \& Pesonen, 2015). No Brasil, o número de anúncios do Airbnb chegou a 123 mil em 2016, sendo 45 mil apenas no Rio de Janeiro (Salomão, 2017). No referido ano, a plataforma movimentou 2 bilhões de reais no Brasil, entre a renda dos anfitriões e o gasto dos hóspedes com turismo. Rio de Janeiro e São Paulo movimentaram 906 milhões de reais e 192 milhões de reais respectivamente. De acordo com Salomão (2017), com o aumento da atividade, o ganho do anfitrião também ficou mais alto e o ganho anual foi de 6.070 reais.

Em Portugal, segundo Ferreira (2017), o Airbnb começou a ter notoriedade a partir de meados de 2013, mais especificamente em Lisboa, quando se chegou ao total de 1600 anúncios na plataforma. Ferreira (2017) relata que, até abril de 2017, Lisboa contou com cerca de 12 mil anúncios; Faro contou com aproximadamente 11 mil anúncios; o Porto contou com 4900 anúncios; Madeira contou com 2500 anúncios aproximadamente; e Coimbra tinha cerca de 1100 anúncios. Como se verifica, Lisboa e Faro destacam-se claramente no território português.

\subsection{Apresentação dos construtos do modelo teórico e desenvolvimento de hipóteses}

O modelo teórico do estudo apresentou os seguintes constructos: a Expectativa de Desempenho, a Expectativa de Esforço, a Influência Social, as Condições Facilitadoras, a Economia de Custos, a Expectativa de Experiências Culturais Compartilhadas e de Construção de Vínculos Sociais, Perspectiva Anti-indústria, a Confiança, o Grau de Identificação entre Pares e a Percepção de Cocriação de Valor. Tal modelo teórico foi utilizado para estudar a plataforma paga de economia da partilha Airbnb.

\section{- Expectativa de desempenho}

Inicialmente, no modelo teórico UTAUT (Unified Theory of Acceptance and Use of Technology), desenvolvido para o estudo de aceitação e uso de tecnologia em ambiente organizacional, a Expectativa de Desempenho tinha o objetivo de avaliar em qual medida o sujeito acredita que a utilização do sistema contribuirá para a melhora do desempenho em seu trabalho (Venkatesh, Morris, Davis \& Davis, 2003). Com o desdobramento do UTAUT para o estudo de aceitação e uso de tecnologias no contexto do consumo, no UTAUT 2, a Expetativa de Desempenho passou a corresponder à variável que visa avaliar em qual medida os sujeitos acreditam que a utilização de determinada tecnologia proporcionará benefícios para eles enquanto consumidores (Venkatesh et al., 2003; Venkatesh, Thong \& Xu, 2012).

No modelo original, Venkatesh et al. (2003) verificaram que a Expectativa de Performance é o preditor mais forte de intenção de uso de uma tecnologia. Nos resultados dos estudos de Indrawati e Haryoto (2015), tal relação também foi confirmada. Assim, formulou-se a hipótese inicial de que a Expectativa de Desempenho avalia a contribuição que a plataforma de economia compartilhada de turismo pode proporcionar na vida das pessoas em termos de utilidade e benefícios percebidos.

H1: A Expectativa de Desempenho tem correlação positiva com a Propensão para a utilização de plataformas de economia compartilhada de turismo. 


\section{- Expectativa de esforço}

A Expectativa de Esforço, no modelo UTAUT, corresponde, segundo Venkatesh et al. (2003), à perspectiva de facilidade pelo indivíduo em relação à utilização do sistema. Os autores explicam que o construto Expectativa de Esforço é significativo tanto em contextos em que a adoção do sistema se dá de maneira voluntária, quanto em circunstâncias em que o uso é obrigatório. No UTAUT 2, voltado para o contexto do consumo, a Expectativa de Esforço refere-se ao grau de facilidade associado ao uso de determinada tecnologia pelos consumidores. É a perspectiva de facilidade pelo indivíduo em relação à utilização do sistema (Venkatesh et al., 2003; Venkatesh et al., 2012).

Venkatesh et al. (2012) hipotetizaram que a Expectativa de Esforço teria uma relação positiva com a Intenção de Uso de mobile marketing. Estudos posteriores aplicados em contextos distintos como o de Giglio, Pinochet, Lopes e Azevedo (2017) também confirmaram tal relação. Neste sentido, em relação às plataformas de economia compartilhada de turismo, propôs-se a hipótese inicial para verificar se elas proporcionam uma interface de fácil aprendizado e utilização por parte dos consumidores.

H2: A Expectativa de Esforço tem correlação positiva com a Propensão para a utilização de plataformas de economia compartilhada de turismo.

\section{- Influência social}

No modelo UTAUT, o construto Influência Social é definido por Venkatesh et al. (2003) como a intensidade na qual o indivíduo compreende a influência que pessoas importantes em seu círculo social exercem sobre ele no sentido da utilização do sistema, na intenção comportamental de uso. Já no UTAUT 2, a Influência Social visa avaliar em que medida os consumidores percebem como importantes o que os outros (por exemplo, família e amigos) acreditam sobre o uso de uma determinada tecnologia. É conceituado como a intensidade na qual o sujeito compreende a influência que pessoas importantes em seu círculo social exercem para que ele utilize a tecnologia (Venkatesh et al., 2003; Venkatesh et al., 2012).

A suposição fundamental é que os indivíduos tendem a consultar sua rede social sobre o uso de novas tecnologias e podem ser influenciados pela pressão social percebida de outras pessoas consideradas importantes. No contexto de consumo, os não-usuários têm maior controle de suas escolhas e as consequências destas sobre sua imagem social, de modo que a influência social desempenha um papel significativo no comportamento do consumidor (Slade, Dwivedi, Piercy \& Williams, 2015).

Em estudos anteriores como o de Indrawati e Haryoto (2015), a relação entre a Influência Social e Intenção de Uso foi confirmada. No presente estudo, a Influência Social avalia basicamente três tipos de pessoas que podem influenciar e estimular o uso de plataformas de economia compartilhada no turismo: (i) as pessoas que são importantes para o indivíduo, (ii) as pessoas que influenciam o comportamento do indivíduo e (iii) as pessoas cujas opiniões são valorizadas pelo indivíduo. Em alguns casos, uma mesma pessoa pode assumir dois, ou até mesmo três destes papéis de influência. Propõe-se, portanto, mais uma hipótese: 
H3: A Influência Social tem correlação positiva com a Propensão para a utilização de plataformas de economia compartilhada de turismo.

\section{- Condições facilitadoras}

No contexto organizacional, estudado pelo modelo UTAUT, o construto Condições Facilitadoras é conceituado por Venkatesh et al. (2003) como o nível de confiança do indivíduo na existência de infraestrutura técnica e suporte para a utilização do sistema. No contexto de consumo, para o qual o modelo UTAUT 2 se volta, o construto Condições Facilitadoras visa medir as percepções dos consumidores no que diz respeito aos recursos e apoio disponível para executar uma conduta (Venkatesh et al., 2003; Venkatesh et al., 2012).

Elas são consideradas fatores ambientais que facilitam ou impedem a aceitação da tecnologia. Incluem muitos aspectos que podem influenciar diretamente o comportamento real, como o treinamento ou o conhecimento que os indivíduos possuem (Chang, 2012). Algumas plataformas de economia compartilhada de turismo podem exigir mais conhecimento ou recursos dos usuários do que as outras. Como resultado, o conhecimento de como utilizá-las também pode influenciar o uso contínuo dos usuários. Os usuários com um melhor conhecimento de como utilizá-las são mais propensos a continuar usando-as (Yuan, Ma, Kanthawala \& Peng, 2015). Por isso, formula-se a hipótese:

H4: As Condições Facilitadoras têm correlação positiva com a Propensão para a utilização de plataformas de economia compartilhada de turismo.

\section{- Economia de custos}

A Economia de Custos foi indicada por alguns autores como um dos principais fatores motivadores para as pessoas optarem pela economia compartilhada (Bardhi \& Eckhardt, 2012; Botsman \& Rogers, 2011; Lamberton \& Rose, 2012). Belk e Sobh (2007), por exemplo, apontam que o compartilhamento possibilita que as pessoas consumam um conjunto maior e mais variado de coisas do que elas poderiam pagar e que, devido a isso, economizar custos pode corresponder a uma motivação. Os autores chamam atenção para o fato de que é possível que haja risco de perda ou danos a depender de como o compartilhamento se proceda, porém eles expõem que, se todas as partes agirem de acordo com as regras, é possível que todos ganhem. Seguindo esta lógica, a Economia de Custos seria uma motivação que superaria, por exemplo, o medo de perda ou os danos.

Lamberton e Rose (2012), por sua vez, sugerem que sistemas de consumo colaborativo, como plataformas de compartilhamento de carro (a exemplo do Zipcar), podem ser preferidos porque eles permitem o acesso ao produto/serviço desejado a um baixo custo. Assim, a economia de custos seria um fator, na visão dos autores, consistente com modelos racionais, em que os consumidores buscam produtos que ofereçam a maior quantidade de benefícios no menor custo possível. Tal perspectiva apresenta sintonia com a de Sacks (2011) que afirmou que os consumidores participam da economia compartilhada porque ela permite acesso a produtos e serviços a baixo custo, sugerindo uma recompensa extrínseca de economia de custos dos sistemas P2P (Peer-to-peer). 
H5: A Economia de Custos tem correlação positiva com a Propensão para a utilização de plataformas de economia compartilhada de turismo.

- Expectativa de experiências culturais compartilhadas e de construção de vínculos sociais

Heo (2016) aponta que o desejo de conexão com a comunidade local pode ser um fator que contribui para a popularidade da economia compartilhada no turismo. Em complemento, Tussyadiah e Pesonen (2015) afirmam que participar dessas plataformas permite que as pessoas criem e mantenham conexões sociais, tendo interações diretas com os hosts e possibilitando a conexão com as comunidades locais e uma experiência local única. Já Liang, Choi e Joppe (2018) expuseram, baseados em estudos anteriores, que a busca de experiências de vida local corresponderia a um atrativo para os consumidores do Airbnb. Neste sentido, a Expectativa de Experiências Culturais Compartilhadas pode ser um fator que tem correlação positiva com a propensão para a utilização de plataformas de economia compartilhada de turismo.

A partir do que foi abordado pela literatura apontada acima, é possível formular uma definição do construto Expectativa de Experiências Culturais Compartilhadas como o desejo de conexão com a comunidade local e experiências únicas e autênticas. Guttentag (2015) complementa que os turistas esperam que as experiências sociais de permanecer com os locais levem a experiências de viagem mais autênticas. Ao considerar estes aspectos, formula-se a seguinte hipótese:

H6: A Expectativa de Experiências Culturais Compartilhadas e de Construção de Vínculos Sociais tem correlação positiva com a Propensão para a utilização de plataformas de economia compartilhada de turismo.

\section{- Perspectiva anti-indústria}

Para Botsman e Rogers (2011), a opção pelo consumo da economia compartilhada pode representar também uma rejeição de uma aquisição materialista via mercado competitivo. Neste sentido, este tipo de consumo pode ter um significado associado com "desconsumo" e "anticonsumo" (Ozanne \& Ballantine, 2010). Para estes mesmos autores, o compartilhamento não é uma forma extrema de ativa revolta contra o mercado, mas possivelmente é mais parecido com comportamentos de minimização. Os autores argumentam que o compartilhamento pode também ser conceituado como uma forma "fútil" de resistência ao mercado, que permite aos consumidores consumir menos por escolherem compartilhar em vez de comprar os próprios bens. Isso pode indicar o aparecimento de culturas, subculturas, grupos e comunidades que atrelam interesses pessoais às atividades de consumo.

Neste sentido, é possível considerar a perspectiva anti-indústria como um possível antecedente para a utilização de plataformas de economia compartilhada no turismo. Sendo assim, formula-se a seguinte hipótese do estudo: 
H7: A Perspectiva Anti-Indústria tem correlação positiva com a Propensão para a utilização de plataformas de economia compartilhada de turismo.

\section{- Confiança}

As plataformas de economia compartilhada operam a partir da ideia de relacionamento entre pares que não se conhecem. Para Möhlmann (2015), no contexto do consumo colaborativo, a confiança simultaneamente refere-se à confiança no provedor do serviço de consumo colaborativo e nos outros consumidores com os quais se está compartilhando. Neste sentido, nota-se que as impressões a respeito dos atributos dos hosts e dos serviços descritos na plataforma e disponibilizados nas mídias sociais têm um papel importante no estabelecimento da confiança.

Ert, Fleischer e Magen (2016) argumentam que a confiança é um sentimento subjetivo em que o consumidor se comportará em um determinado sentido de acordo com a promessa implícita ou explícita feita. É um ingrediente fundamental para transações online peer-topeer, uma vez que dois estranhos não são susceptíveis de se envolver em uma transação monetária sem confiar uns aos outros (Bonsón Ponte, Carvajal-Trujillo \& Escobar-Rodríguez, 2015). Assim, uma das principais formas de facilitar a confiança no contexto peer-to-peer é a formação de mecanismos de reputação através das avaliações online.

Na visão de Ert, Fleischer e Magen (2016), nas plataformas da economia compartilhada como o Airbnb, a confiança do consumidor é influenciada pela foto pessoal do host. Para eles, o rosto humano é uma fonte de informação social e pode oferecer uma sensação de contato social que falta em relações de e-commerce, por exemplo. Por outro lado, os autores sugerem que, quando os indivíduos vêem fotos pessoais dos outros, eles podem fazer julgamentos precipitados sobre os seus atributos sociais. Kunz e Seshadri (2015) corroboram com Ert, Fleischer e Magen (2016) quando afirmam que a confiança e a simpatia entre os membros das plataformas também são mediadores centrais para o desenvolvimento do relacionamento.

H8: A Confiança tem correlação positiva com a Propensão para a utilização de plataformas de economia compartilhada de turismo.

\section{- Grau de identificação entre os pares (GIP)}

A identificação com o grupo é um determinante chave para a participação na comunidade virtual, de forma que quando a identificação com o grupo é estabelecida, a pessoa desenvolve intenções pensando no "Nós" e quer manter um relacionamento positivo com o grupo (Bagozzi \& Dholakia, 2002), e está propícia a se engajar em atividades da comunidade (Algesheimer, Dholakia \& Hermann, 2005). A ligação entre um indivíduo e os pares precede e contribui para a identificação dele ou dela com o grupo de pares (Algesheimer et al., 2005). Portanto, um relacionamento harmonioso com os pares deve levar os consumidores a buscar e interagir com outros membros similares do grupo, o que pode contribuir para a construção da confiança (Algesheimer et al., 2005). Quanto mais o consumidor tem uma identificação 
com a proposta da plataforma e com o perfil apresentado no site pelo anfitrião, maior é a propensão para confiar neste tipo de serviço. Por isso, formulou-se as seguintes hipóteses:

H9: O Grau de Identificação com o grupo de Pares tem correlação positiva com a Propensão para o Uso de Plataformas de Economia Compartilhada de Turismo.

H10: O Grau de Identificação com o grupo de Pares tem correlação positiva com a Confiança.

\section{- Percepção de cocriação de valor após a experiência com a plataforma}

O conceito de cocriação de valor tem sido muito discutido nos últimos anos sob a perspectiva da Lógica do Serviço Dominante (SDL), introduzida na literatura por Vargo e Lusch (2004). Para os autores, a criação de valor não acontece nas fábricas ou através da distribuição, e sim através de interações de atores compartilhando e usando recursos como habilidades (competências) e conhecimentos. Lusch e Vargo (2014) defendem, portanto, a ideia de que o valor é co-criado e de que é necessária uma lógica que reconheça a primazia dos recursos humanos aplicados em benefício de outras pessoas (e de si próprio).

De acordo com a Lógica do Serviço Dominante, o consumidor é sempre co-criador de valor. O valor surge através do uso da oferta em um contexto particular, em conjunto com recursos providos por outros provedores de serviço. A firma, portanto, não pode criar valor independentemente. A respeito dessa perspectiva de Lusch e Vargo (2014), Baron, Patterson, Warnaby e Harris (2010) comentam que os consumidores não são vistos simplesmente como objetos (recursos operados) a serem alcançados, segmentados e pesquisados, mas como donos de recursos operantes (como habilidades, capacidades, conhecimento, iniciativa e imaginação) que eles integram para criar experiências e valores. Os consumidores fazem parte de uma rede familiar, comercial e social e de comunidades de prática, trazidas junto com a internet (Baron et al., 2010). Eles são, portanto, participantes ativos na criação de experiências, ao invés de recipientes passivos de mensagens de marketing.

Yi e Gong (2013) desenvolveram e validaram uma escala para mensurar o comportamento de cocriação de valor do consumidor. Segundo os autores, pesquisas anteriores identificaram dois tipos de comportamento de cocriação de valor do consumidor: o comportamento de participação do consumidor, que se refere ao comportamento necessário para uma cocriação de valor bem sucedida; e o comportamento de cidadania do consumidor, que é um comportamento voluntário que provê um valor extra à firma mas não é necessariamente requerido para a cocriação de valor (Groth, 2005; Yi \& Gong, 2008; Yi, Nataraajan \& Gong, 2011). O estudo de Yi e Gong (2013) postula que o comportamento de participação do consumidor compreende quatro dimensões: busca por informações, compartilhamento de informações, comportamento responsável e interação pessoal. Já o comportamento de cidadania do consumidor consiste em: feedback, advocacia, ajuda e tolerância.

H11: A Percepção de Cocriação de Valor tem relação positiva com a Propensão para o Uso de Plataformas de Economia Compartilhada de Turismo. 
H12: A Expectativa de Experiências Culturais Compartilhadas e Construção de Vínculos Sociais tem relação positiva com a Percepção de Cocriação de Valor.

A Figura 1 indica o modelo proposto com base na literatura discutida.

Figura 1. Modelo proposto

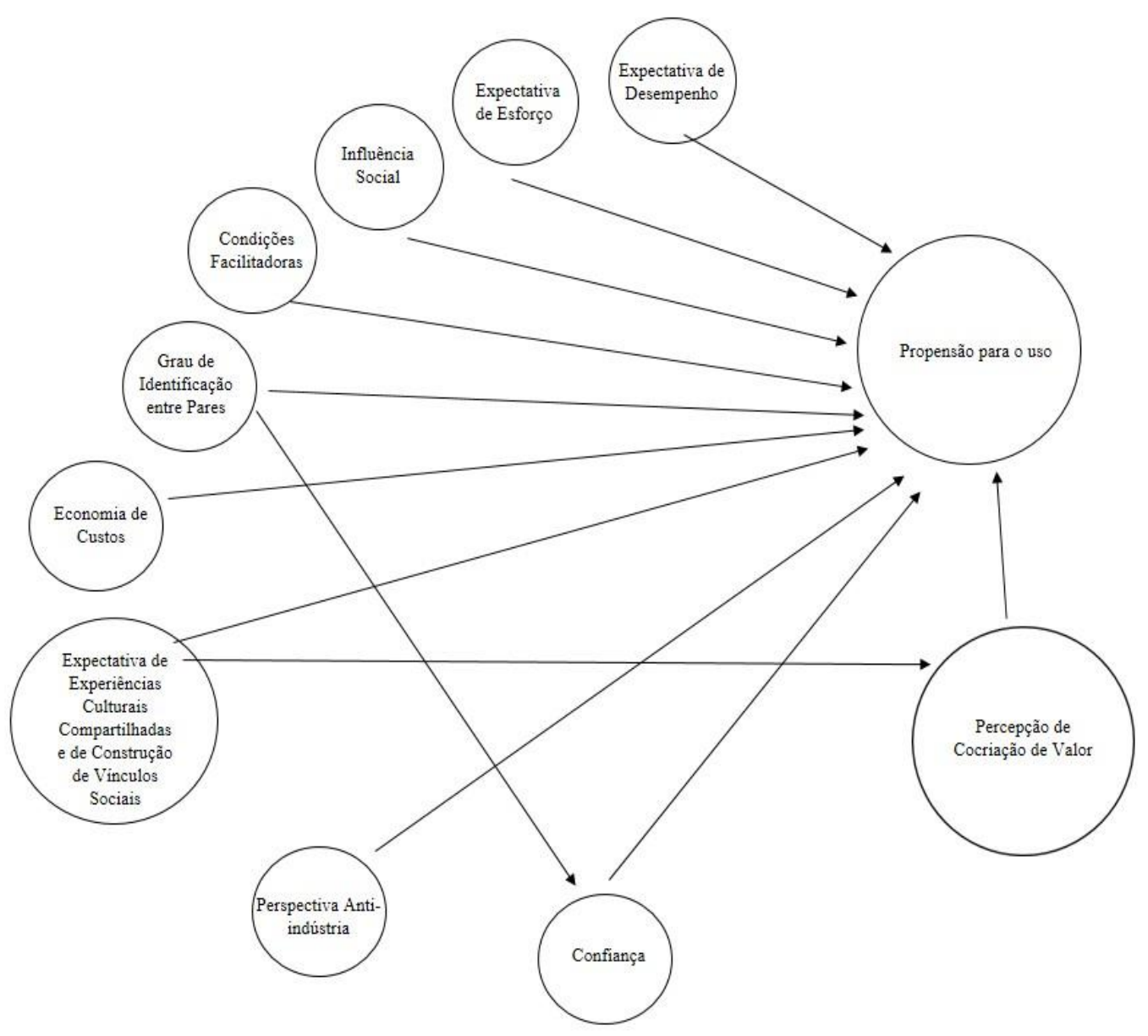

\section{Procedimentos metodológicos}

A pesquisa seguiu abordagem quantitativa. $O$ estudo foi conduzido por meio de um survey, realizado por coleta virtual através da plataforma GoogleForms e presencial com consumidores do Airbnb do Brasil e de Portugal. A amostra utilizada foi do tipo nãoprobabilística por conveniência. No total, obteve-se 454 respostas de pessoas Brasil e 446 de Portugal que já utilizaram o Airbnb como hóspedes pelo menos uma vez na vida.

$O$ instrumento de coleta de dados foi adaptado da literatura e oriundo de um estudo qualitativo anterior, realizado com 20 consumidores Airbnb do Brasil e de Portugal. O estudo qualitativo anterior foi feito por meio de entrevistas em profundidade realizadas no ano de 2017, transcritas e analisadas por meio do método de análise de conteúdo conforme Bardin (1977). 
Para fazer a validação do instrumento de coleta de dados, foi feita uma etapa com painel de especialistas, que incluiu nove investigadores do Brasil (Universidade Federal de Minas Gerais) e dois de Portugal (Universidade do Algarve). O grupo de especialistas avaliou os itens do questionário e ofereceu sugestões que foram adotadas pelos autores. Além disso, também foi aplicado um pré-teste com 23 respondentes no intuito de melhorar o instrumento de coleta de dados. Após essas etapas, foram realizadas alterações no inquérito, de maneira a aprimorar os itens, bem como substituir ou acrescentar novos itens.

O instrumento final de coleta de dados foi composto pelas seguintes variáveis: (1) Expectativa de Desempenho, mensurada pelos indicadores ED1, ED2, ED3 e ED4 provenientes de Venkatesh et al. (2012) e pelo indicador ED5, proveniente de Tussyadiah (2016); (2) Expectativa de Esforço, mensurada pelos indicadores EE1, EE2, EE3 e EE4 provenientes de Venkatesh et al. (2012); (3) Influência Social, mensurada pelos indicadores IS1, IS2 e IS3, provenientes de Venkatesh et al. (2012), e pelo indicador IS4, proveniente de Satama (2014) e Moore e Benbasat (1991); (4) Condições Facilitadoras, mensurada pelos indicadores CF1, CF2, CF3 e CF4, provenientes de Venkatesh et al. (2012), e pelo indicador CF5, proveniente de Satama (2014) e Moore e Benbasat (1991); (5) Grau de Identificação entre os Pares, mensurada por GP1, GP2, GP3 e GP4 provenientes de Wang, Yu e Wei (2012) e etapa qualitativa; (6) Economia de Custos, mensurada pelos indicadores EC1, EC2, EC3 e EC4 provenientes de Tussyadiah (2016), pelos indicadores EC5 EC7, provenientes de etapa qualitativa, e pelo indicador EC6, proveniente de Hamari et al. (2016); (7) Expectativa de Construção de Vínculos Sociais, mensurada pelos indicadores EVS1, EVS2 e EVS3, provenientes de Belk (2010), pelo indicador EVS4 proveniente de etapa qualitativa, e pelo indicador EVS5, proveniente de Möhlmann (2015); (8) Expectativa por Experiências Culturais Compartilhadas, mensurada pelos indicadores EEC1, EEC2, EEC3 e EEC4, provenientes de Tussyadiah (2016), pelo indicador EEC5 proveniente de Liang et al. (2018) e pelos indicadores EEC6, EEC7 e EEC8, provenientes de etapa qualitativa; (9) Perspectiva Anti-Indústria, mensurada pelos indicadores PAl1 e PAl2 provenientes de Lamberton e Rose (2012) e pelos indicadores PAl3 e PAl4 provenientes de etapa qualitativa; (10) Confiança baseada nos feedbacks / avaliações, mensurada pelos indicadores CONF1, CONF2, CONF3, CONF4 e CONF5 provenientes de Liang et al. (2018), e pelos indicadores CONF6, CONF7, CONF8 e CONF9, provenientes de Möhlmann (2015); (11) Propensão para uso das plataformas de economia compartilhada de hospedagem, mensurada por PROUSO1, $\mathrm{PROUSO}_{2}$ e $\mathrm{PROUSO}_{3}$ provenientes de Lamberton e Rose (2012) e PROUSO4, proveniente de Tussyadiah (2016); e (12) Percepção de Cocriação, mensurada por PCC1, PCC2, PCC3, PCC4, PCC5, PCC6, PCC7, PCC8, PCC9 e PCC10, provenientes de Yi e Gong (2013), e PCC11, PCC12 e PCC13, provenientes da etapa qualitativa do estudo.

Para mensuração das variáveis presentes no questionário, escolheu-se a utilização de escala intervalar do tipo Likert de 7 pontos, variando de "Discordo totalmente" a "Concordo totalmente". Para auxiliar a análise dos dados, foram utilizados os softwares SPSS e SmartPLS 3. Inicialmente, foi feita uma análise descritiva das amostras com o objetivo de oferecer uma descrição do perfil dos respondentes. Após esta etapa, realizou-se o processo de preparação dos dados (dados ausentes, verificação de outliers, linearidade e 
normalidade). Por fim, os dados foram analisados por meio de análise fatorial exploratória e de modelagem de equações estruturais (PLS-SEM).

A razão subjacente à escolha da técnica PLS-SEM foi que ela é preferida em situações nas quais o objetivo da pesquisa é o desenvolvimento de teoria e a predição de constructos (Hair, Black, Babin \& Anderson, 2014a). O modelo teórico do estudo foi do tipo reflexivo. Os constructos foram modelados como reflexivos, porque os estudos que basearam o modelo teórico empregaram a modelagem como reflexiva. Além disso, a escolha foi baseada no raciocínio de que os indicadores seriam consequência do constructo.

\section{Resultados}

\subsection{Perfil das amostras do Airbnb do Brasil e de Portugal}

A maioria dos respondentes do Brasil foi do sexo feminino, uma vez que 295 são mulheres, o que significa $65 \%$ do total, e 159 são homens, o que representa 35\%. As idades dos respondentes do Brasil variaram entre 18 e 67 anos. Em relação ao nível de escolaridade dos respondentes, 25\% (113 pessoas) afirmou ter nível superior completo, 23\% (106) têm nível superior incompleto, 21\% (96 pessoas) têm mestrado, 21\% (94) têm especialização (pósgraduação, MBA e outros) e $9 \%$ (39) declararam ter doutorado.

No total, 446 pessoas de Portugal responderam ao questionário afirmando que já utilizaram o Airbnb como hóspedes pelo menos uma vez na vida. Em relação ao gênero dos respondentes, $51 \%$ deles são homens e $49 \%$ são mulheres. As idades dos respondentes de Portugal variaram entre 19 e 65 anos. No que diz respeito às habilitações literárias dos respondentes de Portugal, 165 pessoas (37\%) afirmaram ter pós-graduação, 156 (35\%) pessoas têm ensino superior completo, 83 pessoas (19\%) afirmaram ter até o ensino secundário e 42 pessoas afirmaram ter doutoramento ( $9 \%$ ). Notou-se, assim, que o nível de escolaridade dos respondentes de Portugal é alto.

\subsection{Análise de normalidade e de linearidade}

Para avaliar a normalidade dos dados, foi realizado o teste Kolgomorov-Smirnov, que calcula o nível de significância para as diferenças em relação a uma distribuição normal. Os resultados dos testes feitos na amostra do Brasil e na amostra de Portugal indicaram o valor $\mathrm{p}=0,000$ para todas as variáveis. Assim, todos os valores $\mathrm{p}$ foram menores que 0,005, o que significa que a hipótese de que a distribuição é normal foi rejeitada e atesta a não normalidade em todas as variáveis.

O teste de linearidade serve para avaliar se o modelo possui as propriedades de aditividade e homogeneidade (Hair, Anderson, Tatham \& Black, 2009). Para avaliar a linearidade dos dados, foi feito o teste Spearman, utilizado em casos de amostras com distribuições não normal. Todos os testes tanto da amostra do Brasil quanto da amostra de Portugal entre os indicadores do mesmo construto apresentaram correlações significativas a 0,01 (2 extremidades). A análise de correlação da matriz total revelou que as relações da matriz foram lineares ( $1 \%$ bicaudal) em sua maioria. 


\subsection{Análise fatorial exploratória (AFE)}

Como o presente estudo desenvolveu e adequou escalas específicas para o contexto da economia compartilhada no turismo, julgou-se importante entender a forma de agrupamento dos fatores existentes entre os itens da pesquisa. Neste sentido, foi realizada a análise fatorial exploratória (AFE). A AFE analisa as estruturas de correlações entre as variáveis definindo um conjunto de dimensões latentes comuns (Hair et al., 2009). Para a AFE, foi utilizada a comunalidade, as cargas fatoriais, o KMO e teste de Bartlett.

A análise fatorial exploratória da amostra Airbnb (Brasil) foi conduzida primeiramente por meio da extração por componentes principais e rotação ortogonal varimax, com todos os construtos do modelo. Os resultados do teste de esfericidade de Barlett (sig 0,000) e do Kaiser-Meyer-Olkin (KMO) $(0,907)$ mostraram-se adequados, já que o ideal é que o valor da significância do teste de esfericidade de Barlett seja menor que 0,05 e que o valor do KMO esteja entre 0,5 e 1,0 (Hair et al., 2014a).

Nesta primeira rodada, todas as comunalidades foram acima de 0,4 , respeitando os parâmetros indicados por Hair et al. (2014a). O total da variância explicada foi de $71 \%$, mostrando-se de acordo com o parâmetro de que o ideal é que seja superior a $60 \%$. $\mathrm{Na}$ realização da primeira rodada da AFE, 14 fatores foram extraídos.

A análise fatorial exploratória da amostra (Portugal) foi inicialmente conduzida com todos os construtos no intuito de encontrar a estrutura de fatores presente no modelo como um todo. Posteriormente, a AFE foi conduzida construto por construto com o objetivo de avaliar a unidimensionalidade de todos os construtos do modelo. No primeiro momento, a AFE foi realizada por meio da extração por componentes principais e rotação ortogonal varimax. Notou-se que os resultados indicaram a adequabilidade da análise fatorial por meio do KMO $(0,919)$ e Barlett's (sig 0,000).

O resultado da primeira rodada da AFE da amostra (Portugal) indicou que todas as comunalidades foram acima de 0,4. Quatorze fatores foram extraídos com variância extraída de $76 \%$.

\subsection{Análise do modelo de mensuração}

Os critérios utilizados para avaliar o modelo de mensuração dos construtos reflexivos, incluem a confiabilidade simples e composta, validade convergente (AVE e cargas externas), validade discriminante (cargas cruzadas, Fornell-Larcker e HTMT). A Figura 2 apresenta 0 modelo teórico reduzido relacionado à plataforma de consumo colaborativo Airbnb. 
Figura 2. Modelo teórico reduzido relacionado à plataforma de consumo colaborativo Airbnb $\left(n .^{\circ} 1\right)$

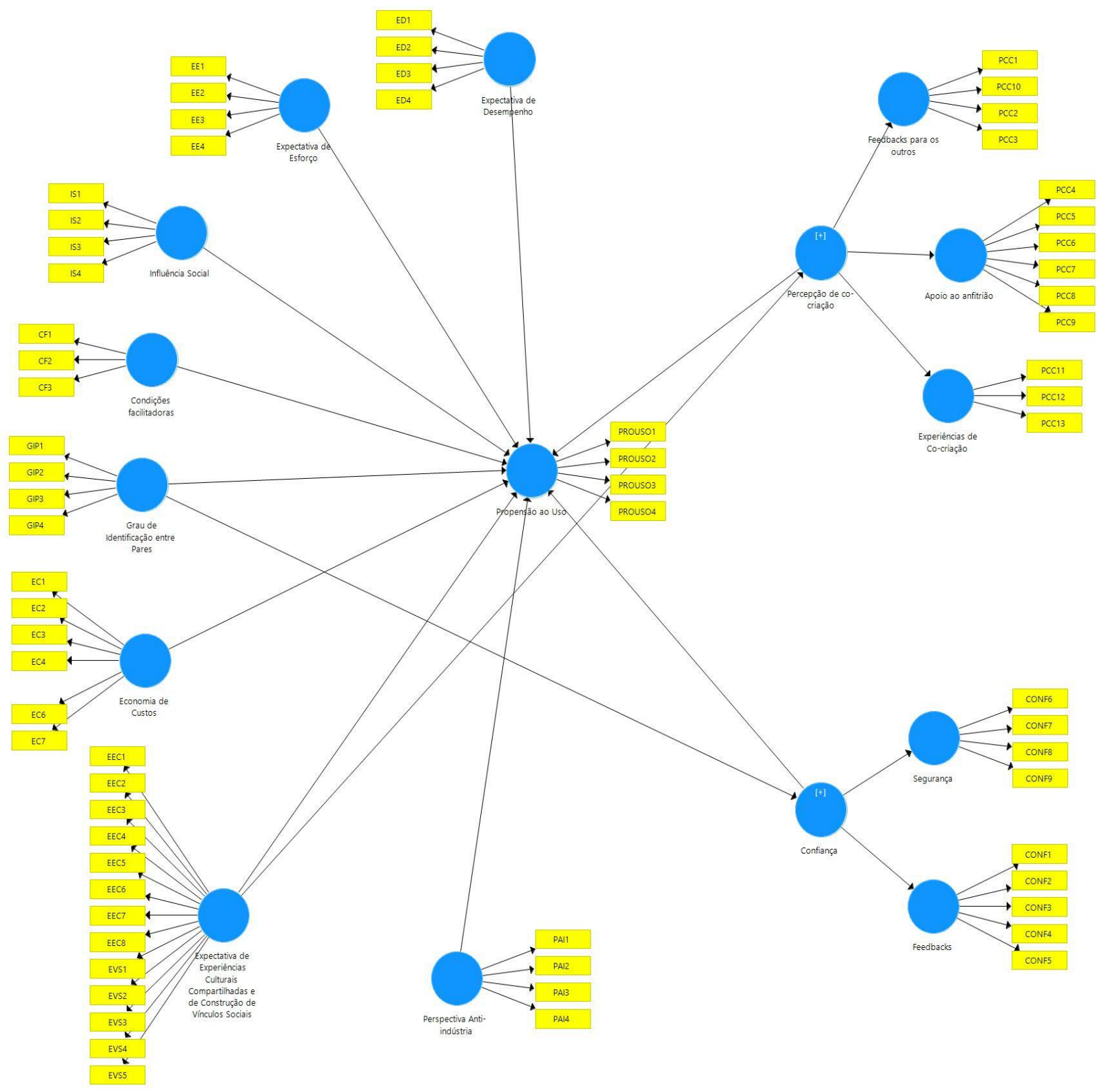

Fonte: Saída SMART PLS (2019).

Os dados foram rodados com o PLS Algoritmo consistente. No decorrer das análises das amostras do Brasil e de Portugal, alguns indicadores apresentaram carga externa com valor muito abaixo do que é indicado pela literatura (abaixo de 0,40). Neste sentido, após algumas repetições do procedimento do PLS Algoritmo consistente, foi necessário retirar indicadores, vide a Figura 3. 
Figura 3. Modelo teórico relacionado à plataforma de compartilhamento Airbnb após a retirada de itens com cargas externas abaixo de $0,4\left(n .^{\circ} 2\right)$

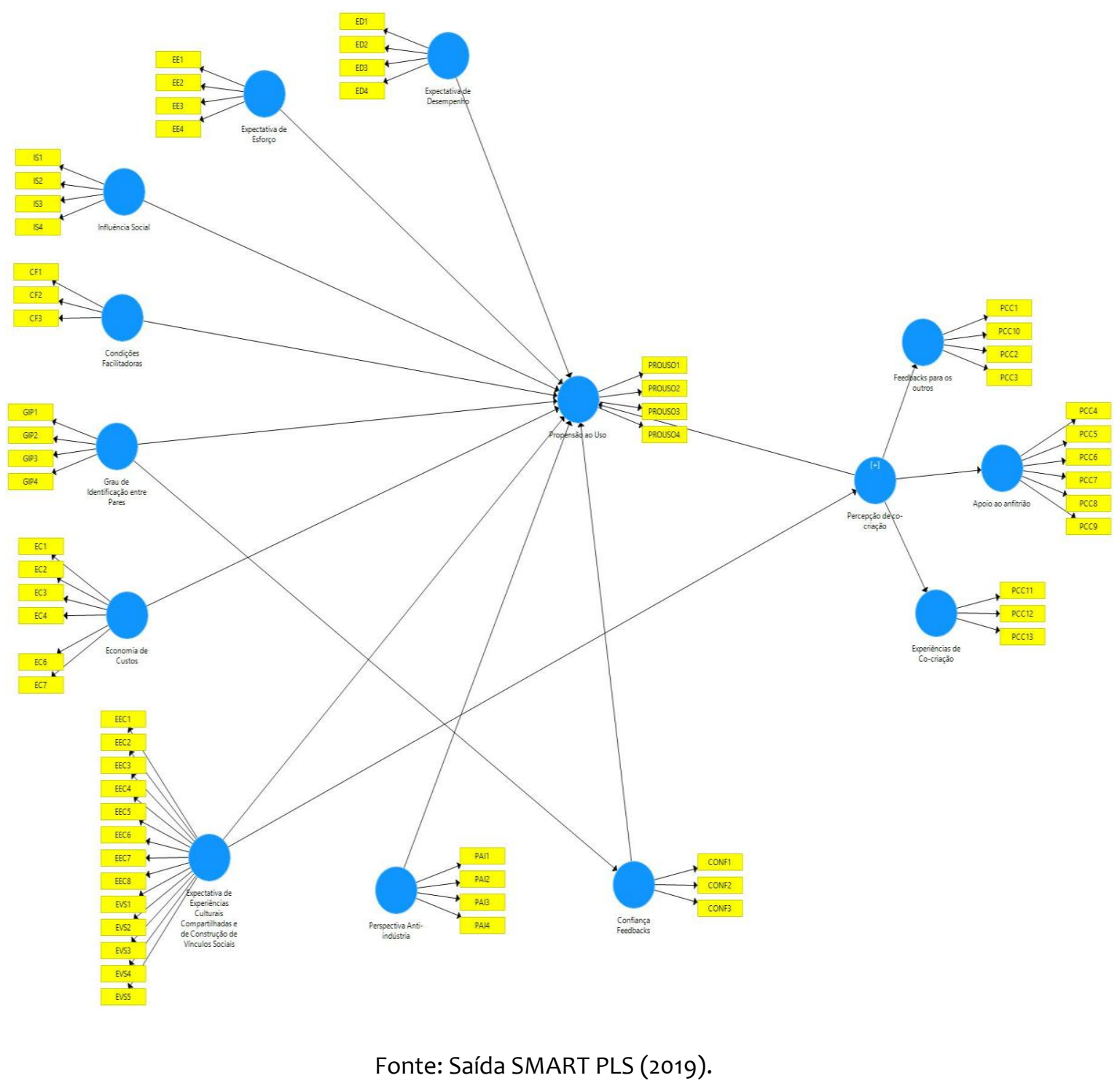

\subsection{Avaliação do modelo de mensuração (Brasil)}

A Figura 4 apresenta o modelo de mensuração referente à amostra do Brasil. 
Figura 4. Modelo de mensuração (Brasil)

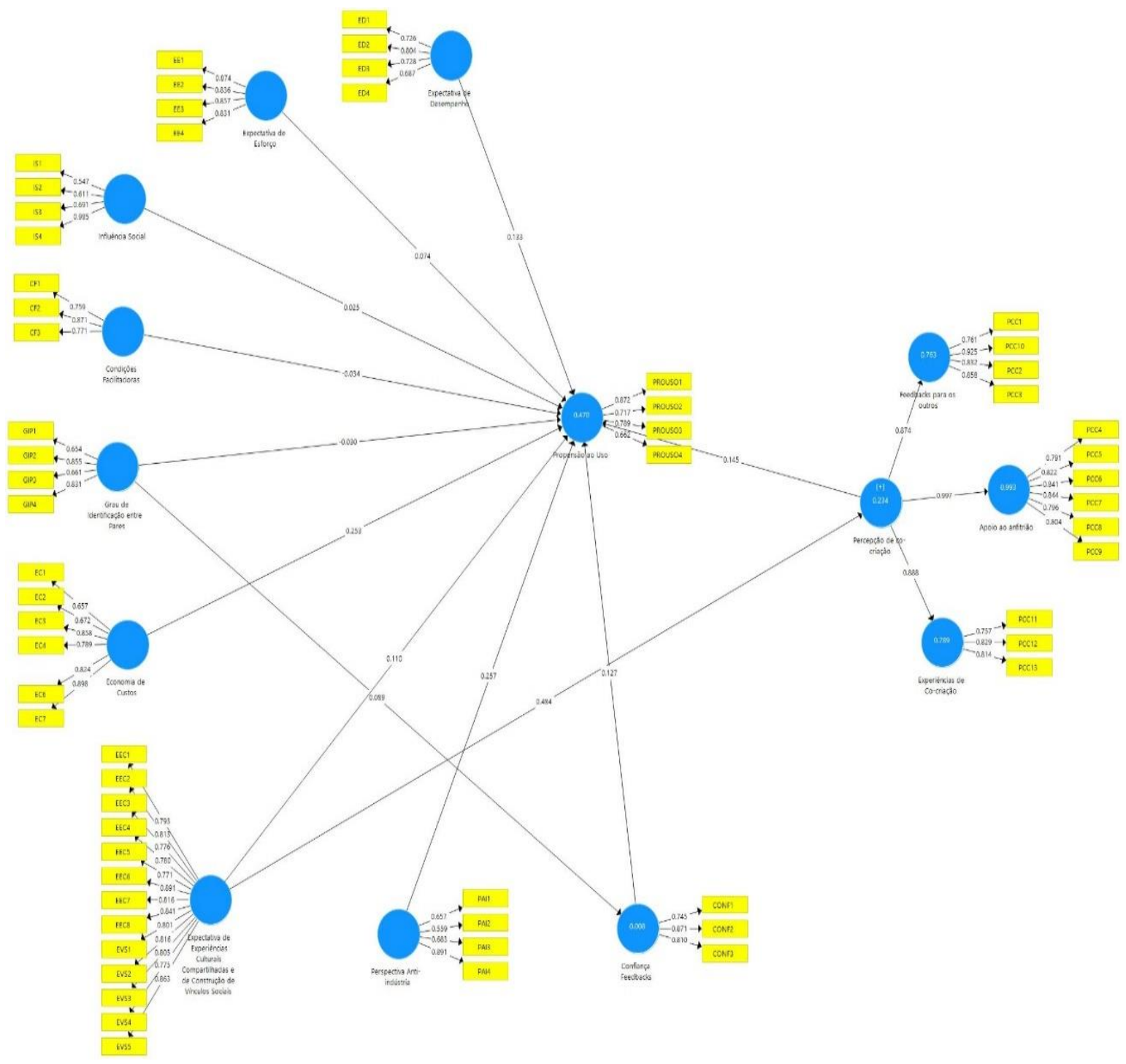

Fonte: Saída SMART PLS (2019).

\section{- Confiabilidade simples e confiabilidade composta}

A análise da confiabilidade foi realizada a partir dos valores do alpha de Cronbach e da confiabilidade composta. Todos os valores estiveram acima de 0,7 e foram, portanto, satisfatórios, conforme pode ser observado na Tabela 1. 
Tabela 1. Confiabilidade simples e composta do modelo de mensuração da amostra (Brasil)

\begin{tabular}{|l|r|r|}
\hline \multicolumn{1}{|c|}{ Construto } & \multicolumn{2}{c|}{ Airbnb Brasil } \\
\hline \multicolumn{1}{|c|}{$\begin{array}{c}\text { Confiabilidade } \\
\text { Simples }\end{array}$} & $\begin{array}{c}\text { Confiabilidade } \\
\text { Composta }\end{array}$ \\
\hline Condições Facilitadoras & 0,841 & 0,844 \\
\hline Confiança baseada nos Feedbacks & 0,849 & 0,851 \\
\hline Economia de Custos & 0,913 & 0,907 \\
\hline Expectativa de Desempenho & 0,826 & 0,826 \\
\hline Expectativa de Esforço & 0,912 & 0,912 \\
\hline $\begin{array}{l}\text { Expectativa de Experiências Culturais Compartilhadas } \\
\text { e de Construção de Vínculos Sociais }\end{array}$ & 0,962 & 0,962 \\
\hline Grau de Identificação entre Pares & 0,843 & 0,840 \\
\hline Influência Social & 0,832 & 0,810 \\
\hline Percepção de cocriação & 0,931 & 0,931 \\
\hline Perspectiva Anti-indústria & 0,793 & 0,796 \\
\hline Propensão ao Uso & 0,844 & 0,847 \\
\hline
\end{tabular}

- Validade convergente

Os resultados da análise da validade convergente da amostra (Brasil) indicaram que todos os valores estiveram adequados aos parâmetros, vide Tabelas 3 e 4 . Todos os valores da AVE estiveram acima de 0,5, conforme pode ser visto na Tabela 2.

Tabela 2. Variância média extraída (AVE) da amostra (Brasil)

\begin{tabular}{|l|r|}
\hline \multicolumn{1}{|c|}{ Construto } & \multicolumn{1}{c|}{ Airbnb Brasil } \\
\hline Condições facilitadoras & \multicolumn{1}{c|}{ AVE } \\
\hline Confiança baseada nos Feedbacks & 0,643 \\
\hline Economia de Custos & 0,657 \\
\hline Expectativa de Desempenho & 0,621 \\
\hline Expectativa de Esforço & 0,544 \\
\hline Expectativa de Experiências Culturais Compartilhadas e de Construção de & 0,722 \\
Vínculos Sociais & 0,659 \\
\hline Grau de Identificação entre Pares & 0,571 \\
\hline Influência Social & 0,530 \\
\hline Percepção de cocriação & 0,511 \\
\hline Perspectiva Anti-indústria & 0,501 \\
\hline Propensão ao Uso & 0,584 \\
\hline
\end{tabular}


Tabela 3. Avaliação das cargas externas dos construtos de primeira ordem da amostra (Brasil)

\begin{tabular}{|c|c|c|}
\hline Construto & Indicadores & Outer Loadings \\
\hline \multirow{3}{*}{ Condições Facilitadoras } & CF1 & 0,759 \\
\hline & CF2 & 0,871 \\
\hline & $\mathrm{CF}_{3}$ & 0,771 \\
\hline \multirow{3}{*}{ Confiança baseada nos Feedbacks } & CONF1 & 0,745 \\
\hline & CONF2 & 0,871 \\
\hline & $\mathrm{CONF}_{3}$ & 0,810 \\
\hline \multirow{6}{*}{ Economia de Custos } & EC1 & 0,657 \\
\hline & $\mathrm{EC2}$ & 0,672 \\
\hline & EC3 & 0,858 \\
\hline & $\mathrm{EC}_{4}$ & 0,789 \\
\hline & EC6 & 0,824 \\
\hline & EC7 & 0,898 \\
\hline \multirow{4}{*}{ Expectativa de Desempenho } & ED1 & 0,726 \\
\hline & ED2 & 0,804 \\
\hline & ED3 & 0,728 \\
\hline & ED4 & 0,687 \\
\hline \multirow{4}{*}{ Expectativa de Esforço } & EE1 & 0,874 \\
\hline & EE2 & 0,836 \\
\hline & EE3 & 0,857 \\
\hline & EE4 & 0,831 \\
\hline \multirow{13}{*}{$\begin{array}{c}\text { Expectativa de Experiências } \\
\text { Culturais Compartilhadas e de } \\
\text { Vínculos Sociais }\end{array}$} & EEC1 & 0,793 \\
\hline & EEC2 & 0,813 \\
\hline & $\mathrm{EEC}_{3}$ & 0,776 \\
\hline & EEC4 & 0,780 \\
\hline & EEC5 & 0,771 \\
\hline & EEC6 & 0,891 \\
\hline & EEC7 & 0,816 \\
\hline & EEC8 & 0,841 \\
\hline & EVS1 & 0,801 \\
\hline & EVS2 & 0,816 \\
\hline & EVS3 & 0,805 \\
\hline & EVS4 & 0,775 \\
\hline & EVS5 & 0,863 \\
\hline \multirow{4}{*}{ Grau de Identificação entre Pares } & GIP1 & 0,654 \\
\hline & GIP2 & 0,855 \\
\hline & $\mathrm{GIP}_{3}$ & 0,661 \\
\hline & GIP4 & 0,831 \\
\hline \multirow{4}{*}{ Influência Social } & IS1 & 0,547 \\
\hline & IS2 & 0,611 \\
\hline & IS3 & 0,691 \\
\hline & IS4 & 0,985 \\
\hline \multirow{4}{*}{ Perspectiva Anti-indústria } & PAl1 & 0,657 \\
\hline & PAl2 & 0,559 \\
\hline & $\mathrm{PAI} 3$ & 0,683 \\
\hline & $\mathrm{PAI} 4$ & 0,891 \\
\hline \multirow{4}{*}{ Propensão ao Uso } & PROUSO1 & 0,872 \\
\hline & PROUSO2 & 0,717 \\
\hline & $\mathrm{PROUSO}_{3}$ & 0,789 \\
\hline & PROUSO4 & 0,662 \\
\hline
\end{tabular}


Tabela 4. Avaliação das cargas externas do construto de segunda ordem Perceção de Cocriação e de suas dimensões na amostra (Brasil)

\begin{tabular}{|c|c|c|c|c|c|}
\hline $\begin{array}{l}\text { Construto de } \\
\text { segunda ordem }\end{array}$ & Indicadores & $\begin{array}{c}\text { Outer } \\
\text { Loadings }\end{array}$ & $\begin{array}{c}\text { Dimensões do construto de } \\
\text { segunda ordem }\end{array}$ & Indicadores & $\begin{array}{c}\text { Outer } \\
\text { Loadings }\end{array}$ \\
\hline \multirow{13}{*}{$\begin{array}{l}\text { Percepção de } \\
\text { Cocriação }\end{array}$} & PCC1 & 0,6292204 & \multirow{4}{*}{ Feedback para os outros } & PCC1 & 0,7609261 \\
\hline & PCC2 & 0,6828061 & & $P C C_{2}$ & 0,8318679 \\
\hline & $\mathrm{PCC}_{3}$ & 0,6998066 & & $\mathrm{PCC}_{3}$ & 0,8580015 \\
\hline & PCC10 & 0,7292651 & & PCC10 & 0,9251264 \\
\hline & $\mathrm{PCC}_{4}$ & 0,6852667 & \multirow{6}{*}{ Apoio ao anfitrião } & $\mathrm{PCC}_{4}$ & 0,7913164 \\
\hline & PCC5 & 0,7349678 & & PCC5 & 0,8220557 \\
\hline & PCC6 & 0,7520137 & & PCC6 & 0,8406145 \\
\hline & PCC7 & 0,7549384 & & PCC7 & 0,8437762 \\
\hline & PCC8 & 0,696672 & & PCC8 & 0,7955357 \\
\hline & PCC9 & 0,7059751 & & PCC9 & 0,8042075 \\
\hline & PCC11 & 0,7032878 & \multirow{3}{*}{ Experiências de cocriação } & PCC11 & 0,7569034 \\
\hline & PCC12 & 0,76074 & & PCC12 & 0,8291927 \\
\hline & PCC13 & 0,7502125 & & PCC13 & 0,8144808 \\
\hline
\end{tabular}

\section{- Validade discriminante}

Para a análise da validade discriminante, foram considerados o critério de Fornell-Larcker, as cargas cruzadas e o critério HTMT. Todos os resultados obtidos podem ser conferidos nas Tabelas 5, 6 e 7 e foram considerados adequados conforme os parâmetros indicados por Hair, Hult, Ringle e Sarstedt (2014b).

Tabela 5. Validade discriminante - Critério Fronell Larcker na amostra (Brasil)

\begin{tabular}{|c|c|c|c|c|c|c|c|c|c|c|c|c|c|c|}
\hline & $\begin{array}{l}\text { Apoio } \\
\text { ao anf. }\end{array}$ & $\begin{array}{l}\text { Cond. } \\
\text { Facil. }\end{array}$ & Confia & Econ. & $\begin{array}{l}\text { Exp. } \\
\text { Des. }\end{array}$ & $\begin{array}{l}\text { Exp. } \\
\text { Esf. }\end{array}$ & $\begin{array}{l}\text { Exp. } \\
\text { Vinc. }\end{array}$ & $\begin{array}{l}\text { Exp. } \\
\text { Cocri } \\
a \\
\end{array}$ & \begin{tabular}{|l|} 
Feed \\
back \\
5
\end{tabular} & $\begin{array}{l}\text { Grau } \\
\text { Ident }\end{array}$ & $\begin{array}{l}\text { Inf. } \\
\text { Social }\end{array}$ & \begin{tabular}{|l|} 
Perc. \\
Cocri \\
\end{tabular} & $\begin{array}{l}\text { Per. } \\
\text { Antiin } \\
\text { dustria }\end{array}$ & $\begin{array}{l}\text { Prop } \\
\text { uso }\end{array}$ \\
\hline Apoio ao anf. & 0,817 & & & & & & & & & & & & & \\
\hline Cond. Facil. & 0,198 & 0,8 & & & & & & & & & & & & \\
\hline Confianca & 0,35 & 0,23 & 0,81 & & & & & & & & & & & \\
\hline Econ. Cust & 0,163 & 0,22 & 0,13 & 0,79 & & & & & & & & & & \\
\hline Exp. Des. & 0,301 & 0,54 & 0,33 & 0,36 & 0,738 & & & & & & & & & \\
\hline Exp. Esf. & 0,14 & 0,56 & 0,22 & 0,25 & 0,692 & 0,85 & & & & & & & & \\
\hline Exp. Vinc. & 0,376 & 0,15 & 0,15 & 0,38 & 0,306 & 0,23 & 0,81 & & & & & & & \\
\hline Exp. Cocria & 0,721 & 0,2 & 0,23 & 0,23 & 0,3 & 0,19 & 0,64 & 0,8 & & & & & & \\
\hline Feedbacks & 0,652 & 0,16 & 0,28 & 0,16 & 0,336 & 0,21 & 0,33 & 0,54 & 0,85 & & & & & \\
\hline Grau Ident. & 0,292 & 0,31 & 0,09 & 0,23 & 0,297 & 0,25 & 0,54 & 0,43 & 0,32 & 0,76 & & & & \\
\hline Inf. Social & 0,166 & 0,06 & 0,06 & 0,16 & 0,168 & 0,1 & 0,17 & 0,22 & 0,13 & 0,37 & 0,73 & & & \\
\hline Perc. Cocria & 0,997 & 0,22 & 0,35 & 0,21 & 0,357 & 0,2 & 0,48 & 0,89 & 0,87 & 0,38 & 0,2 & 0,72 & & \\
\hline Per. Antiindus & 0,417 & 0,02 & 0,17 & 0,3 & 0,213 & 0,06 & 0,41 & 0,42 & 0,26 & 0,36 & 0,31 & 0,43 & 0,708 & \\
\hline Prop uso & 0,361 & 0,21 & 0,32 & 0,47 & 0,433 & 0,3 & 0,44 & 0,45 & 0,4 & 0,3 & 0,22 & 0,45 & 0,492 & 0,76 \\
\hline
\end{tabular}


Tabela 6. Cargas cruzadas na amostra (Brasil)

\begin{tabular}{|c|c|c|c|c|c|c|c|c|c|c|c|c|c|c|}
\hline & $\begin{array}{l}\text { Apoio } \\
\text { ao } \\
\text { anf. }\end{array}$ & $\begin{array}{l}\text { Cond. } \\
\text { Facil. }\end{array}$ & $\begin{array}{l}\text { Conf. } \\
\text { Feed } \\
\text { backs }\end{array}$ & $\begin{array}{l}\text { Econ. } \\
\text { Cust. }\end{array}$ & $\begin{array}{l}\text { Exp. } \\
\text { Des. }\end{array}$ & $\begin{array}{l}\text { Exp. } \\
\text { Esf. }\end{array}$ & $\begin{array}{l}\text { Exp. } \\
\text { Const } \\
\text { Vínc. } \\
\text { Sociais }\end{array}$ & $\begin{array}{l}\text { Exp. } \\
\text { Cocria } \\
\text { ção }\end{array}$ & $\begin{array}{l}\text { Feed } \\
\text { backs } \\
\text { para } \\
\text { os ou } \\
\text { tros }\end{array}$ & $\begin{array}{l}\text { Grau } \\
\text { Ident. } \\
\text { Pares }\end{array}$ & $\begin{array}{l}\text { Inf. } \\
\text { Soc. }\end{array}$ & $\begin{array}{l}\text { Perc. } \\
\text { Cocria } \\
\text { ção }\end{array}$ & $\begin{array}{l}\text { Per. } \\
\text { Anti } \\
\text { Indus } \\
\text { tria }\end{array}$ & $\begin{array}{l}\text { Pro } \\
\text { Uso }\end{array}$ \\
\hline CF1 & 0,106 & 0,759 & 0,150 & 0,183 & 0,455 & 0,425 & 0,144 & 0,147 & 0,058 & 0,257 & 0,070 & 0,116 & 0,012 & 0,147 \\
\hline $\mathrm{CF} 2$ & 0,176 & 0,871 & 0,218 & 0,177 & 0,456 & 0,487 & 0,140 & 0,184 & 0,162 & 0,269 & 0,028 & 0,199 & $-0,011$ & 0,179 \\
\hline $\mathrm{CF}_{3}$ & 0,193 & 0,771 & 0,183 & 0,177 & 0,380 & 0,437 & 0,086 & 0,143 & 0,164 & 0,222 & 0,046 & 0,198 & 0,038 & 0,173 \\
\hline CONF1 & 0,286 & 0,202 & 0,745 & 0,082 & 0,245 & 0,189 & 0,106 & 0,147 & 0,197 & 0,086 & 0,010 & 0,260 & 0,118 & 0,206 \\
\hline CONF2 & 0,268 & 0,204 & 0,871 & 0,140 & 0,296 & 0,198 & 0,145 & 0,205 & 0,223 & 0,075 & 0,041 & 0,275 & 0,168 & 0,323 \\
\hline $\mathrm{CONF}_{3}$ & 0,299 & 0,154 & 0,810 & 0,077 & 0,261 & 0,136 & 0,118 & 0,205 & 0,258 & 0,057 & 0,091 & 0,304 & 0,127 & 0,241 \\
\hline EC1 & 0,073 & 0,210 & 0,112 & 0,657 & 0,237 & 0,192 & 0,247 & 0,087 & 0,074 & 0,115 & 0,105 & 0,088 & 0,204 & 0,354 \\
\hline$E C 2$ & 0,090 & 0,204 & 0,077 & 0,672 & 0,257 & 0,184 & 0,259 & 0,107 & 0,072 & 0,134 & 0,096 & 0,102 & 0,194 & 0,352 \\
\hline EC3 & 0,161 & 0,206 & 0,130 & 0,858 & 0,315 & 0,228 & 0,312 & 0,197 & 0,148 & 0,192 & 0,082 & 0,190 & 0,229 & 0,418 \\
\hline EC4 & 0,087 & 0,220 & 0,106 & 0,789 & 0,292 & 0,219 & 0,327 & 0,168 & 0,098 & 0,194 & 0,108 & 0,126 & 0,213 & 0,373 \\
\hline EC6 & 0,145 & 0,068 & 0,021 & 0,824 & 0,295 & 0,165 & 0,299 & 0,260 & 0,160 & 0,262 & 0,214 & 0,202 & 0,300 & 0,346 \\
\hline$E C 7$ & 0,194 & 0,164 & 0,142 & 0,898 & 0,298 & 0,192 & 0,355 & 0,250 & 0,172 & 0,171 & 0,147 & 0,230 & 0,285 & 0,399 \\
\hline ED1 & 0,248 & 0,418 & 0,323 & 0,245 & 0,726 & 0,520 & 0,219 & 0,204 & 0,211 & 0,155 & 0,099 & 0,260 & 0,126 & 0,284 \\
\hline ED2 & 0,262 & 0,400 & 0,263 & 0,301 & 0,804 & 0,483 & 0,266 & 0,315 & 0,253 & 0,250 & 0,105 & 0,312 & 0,194 & 0,408 \\
\hline ED3 & 0,190 & 0,350 & 0,189 & 0,290 & 0,728 & 0,493 & 0,217 & 0,183 & 0,297 & 0,276 & 0,164 & 0,253 & 0,212 & 0,329 \\
\hline ED4 & 0,183 & 0,418 & 0,198 & 0,219 & 0,687 & 0,554 & 0,196 & 0,172 & 0,232 & 0,192 & 0,133 & 0,224 & 0,089 & 0,246 \\
\hline EE1 & 0,131 & 0,473 & 0,132 & 0,170 & 0,607 & 0,874 & 0,196 & 0,173 & 0,242 & 0,207 & 0,115 & 0,201 & 0,109 & 0,298 \\
\hline EE2 & 0,112 & 0,500 & 0,191 & 0,192 & 0,593 & 0,836 & 0,172 & 0,169 & 0,165 & 0,205 & 0,090 & 0,162 & 0,029 & 0,205 \\
\hline EE3 & 0,116 & 0,480 & 0,227 & 0,232 & 0,600 & 0,857 & 0,191 & 0,177 & 0,151 & 0,214 & 0,064 & 0,161 & 0,008 & 0,247 \\
\hline EE4 & 0,117 & 0,458 & 0,182 & 0,252 & 0,551 & 0,831 & 0,215 & 0,139 & 0,164 & 0,235 & 0,052 & 0,156 & 0,061 & 0,272 \\
\hline $\mathrm{EEC1}$ & 0,262 & 0,127 & 0,115 & 0,310 & 0,237 & 0,200 & 0,793 & 0,464 & 0,292 & 0,391 & 0,141 & 0,365 & 0,381 & 0,414 \\
\hline $\mathrm{EEC2}$ & 0,319 & 0,160 & 0,114 & 0,326 & 0,252 & 0,180 & 0,813 & 0,504 & 0,256 & 0,413 & 0,161 & 0,394 & 0,356 & 0,353 \\
\hline $\mathrm{EEC} 3$ & 0,347 & 0,119 & 0,109 & 0,272 & 0,209 & 0,179 & 0,776 & 0,496 & 0,245 & 0,410 & 0,120 & 0,402 & 0,306 & 0,334 \\
\hline $\mathrm{EEC} 4$ & 0,301 & 0,124 & 0,119 & 0,292 & 0,195 & 0,156 & 0,780 & 0,497 & 0,273 & 0,447 & 0,093 & 0,388 & 0,320 & 0,339 \\
\hline EEC5 & 0,328 & 0,173 & 0,182 & 0,262 & 0,234 & 0,168 & 0,771 & 0,507 & 0,229 & 0,406 & 0,092 & 0,390 & 0,306 & 0,308 \\
\hline EEC6 & 0,367 & 0,134 & 0,142 & 0,344 & 0,266 & 0,196 & 0,891 & 0,567 & 0,294 & 0,416 & 0,135 & 0,449 & 0,386 & 0,412 \\
\hline EEC7 & 0,296 & 0,150 & 0,155 & 0,345 & 0,245 & 0,172 & 0,816 & 0,542 & 0,241 & 0,411 & 0,135 & 0,386 & 0,322 & 0,379 \\
\hline EEC8 & 0,307 & 0,195 & 0,196 & 0,362 & 0,270 & 0,225 & 0,841 & 0,559 & 0,233 & 0,404 & 0,129 & 0,393 & 0,333 & 0,361 \\
\hline EVS1 & 0,255 & 0,068 & 0,072 & 0,319 & 0,243 & 0,190 & 0,801 & 0,487 & 0,273 & 0,480 & 0,147 & 0,361 & 0,357 & 0,382 \\
\hline EVS2 & 0,295 & 0,215 & 0,161 & 0,392 & 0,347 & 0,260 & 0,816 & 0,507 & 0,220 & 0,379 & 0,133 & 0,369 & 0,233 & 0,399 \\
\hline EVS3 & 0,285 & 0,045 & 0,069 & 0,261 & 0,236 & 0,147 & 0,805 & 0,535 & 0,302 & 0,463 & 0,148 & 0,400 & 0,356 & 0,350 \\
\hline EVS4 & 0,294 & 0,062 & 0,075 & 0,260 & 0,239 & 0,145 & 0,775 & 0,515 & 0,282 & 0,450 & 0,129 & 0,392 & 0,322 & 0,308 \\
\hline EVS5 & 0,309 & 0,056 & 0,100 & 0,285 & 0,248 & 0,177 & 0,863 & 0,513 & 0,315 & 0,580 & 0,236 & 0,411 & 0,388 & 0,324 \\
\hline GIP1 & 0,177 & 0,190 & 0,038 & 0,129 & 0,210 & 0,172 & 0,375 & 0,286 & 0,208 & 0,654 & 0,226 & 0,243 & 0,262 & 0,163 \\
\hline GIP2 & 0,271 & 0,388 & 0,137 & 0,256 & 0,336 & 0,287 & 0,370 & 0,363 & 0,270 & 0,855 & 0,236 & 0,335 & 0,240 & 0,236 \\
\hline $\mathrm{GIP}_{3}$ & 0,168 & 0,121 & $-0,009$ & 0,121 & 0,107 & 0,106 & 0,425 & 0,287 & 0,192 & 0,661 & 0,349 & 0,232 & 0,279 & 0,217 \\
\hline GIP4 & 0,251 & 0,212 & 0,081 & 0,169 & 0,221 & 0,180 & 0,460 & 0,355 & 0,282 & 0,831 & 0,311 & 0,326 & 0,300 & 0,282 \\
\hline IS1 & 0,082 & $-0,019$ & 0,036 & 0,117 & 0,074 & 0,029 & 0,059 & 0,111 & 0,096 & 0,212 & 0,547 & 0,107 & 0,179 & 0,136 \\
\hline
\end{tabular}




\begin{tabular}{|c|c|c|c|c|c|c|c|c|c|c|c|c|c|c|}
\hline & $\begin{array}{l}\text { Apoio } \\
\text { ao } \\
\text { anf. }\end{array}$ & $\begin{array}{l}\text { Cond. } \\
\text { Facil. }\end{array}$ & $\begin{array}{l}\text { Conf. } \\
\text { Feed } \\
\text { backs }\end{array}$ & $\begin{array}{l}\text { Econ. } \\
\text { Cust. }\end{array}$ & $\begin{array}{l}\text { Exp. } \\
\text { Des. }\end{array}$ & $\begin{array}{l}\text { Exp. } \\
\text { Esf. }\end{array}$ & $\begin{array}{l}\text { Exp. } \\
\text { Const } \\
\text { Vínc. } \\
\text { Sociais }\end{array}$ & $\begin{array}{l}\text { Exp. } \\
\text { Cocria } \\
\text { ção }\end{array}$ & $\begin{array}{l}\text { Feed } \\
\text { backs } \\
\text { para } \\
\text { os ou } \\
\text { tros } \\
\end{array}$ & $\begin{array}{l}\text { Grau } \\
\text { Ident. } \\
\text { Pares }\end{array}$ & $\begin{array}{l}\text { Inf. } \\
\text { Soc. }\end{array}$ & $\begin{array}{l}\text { Perc. } \\
\text { Cocria } \\
\text { ção }\end{array}$ & $\begin{array}{l}\text { Per. } \\
\text { Anti } \\
\text { Indus } \\
\text { tria }\end{array}$ & $\begin{array}{l}\text { Pro } \\
\text { Uso }\end{array}$ \\
\hline IS2 & 0,096 & 0,070 & 0,041 & 0,132 & 0,110 & 0,057 & 0,069 & 0,128 & 0,066 & 0,204 & 0,611 & 0,108 & 0,197 & 0,178 \\
\hline $\mathrm{IS}_{3}$ & 0,120 & 0,136 & 0,071 & 0,169 & 0,167 & 0,088 & 0,075 & 0,155 & 0,075 & 0,187 & 0,691 & 0,131 & 0,221 & 0,171 \\
\hline IS4 & 0,168 & $-0,002$ & 0,032 & 0,080 & 0,136 & 0,092 & 0,241 & 0,231 & 0,142 & 0,414 & 0,985 & 0,201 & 0,289 & 0,159 \\
\hline PAl1 & 0,246 & $-0,044$ & 0,131 & 0,313 & 0,124 & 0,009 & 0,261 & 0,221 & 0,170 & 0,246 & 0,230 & 0,249 & 0,657 & 0,340 \\
\hline PAl2 & 0,206 & $-0,020$ & 0,036 & 0,147 & 0,129 & 0,066 & 0,210 & 0,208 & 0,175 & 0,251 & 0,287 & 0,226 & 0,559 & 0,258 \\
\hline PAI3 & 0,291 & 0,022 & 0,127 & 0,173 & 0,127 & 0,008 & 0,286 & 0,284 & 0,174 & 0,223 & 0,242 & 0,292 & 0,683 & 0,358 \\
\hline PAI4 & 0,404 & 0,061 & 0,169 & 0,228 & 0,209 & 0,084 & 0,389 & 0,436 & 0,223 & 0,288 & 0,160 & 0,409 & 0,891 & 0,420 \\
\hline PCC1 & 0,519 & 0,104 & 0,237 & 0,107 & 0,253 & 0,154 & 0,226 & 0,374 & 0,761 & 0,185 & ,094 & 0,706 & 193 & 0,289 \\
\hline PCC1 & 0,519 & 0,104 & 0,237 & 0,107 & 0,253 & 0,154 & 0,226 & 0,374 & 0,940 & 0,185 & 0,094 & 0,629 & 0,193 & 0,289 \\
\hline PCC10 & 0,600 & 0,164 & 0,227 & 0,120 & 0,330 & 0,207 & 0,327 & 0,562 & 0,925 & 0,336 & 0,127 & 0,771 & 0,208 & 0,349 \\
\hline PCC10 & 0,600 & 0,164 & 0,227 & 0,120 & 0,330 & 0,207 & 0,327 & 0,562 & 0,868 & 0,336 & 0,127 & 0,729 & 0,208 & 0,349 \\
\hline PCC11 & 0,493 & 0,181 & 0,146 & 0,228 & 0,261 & 0,158 & 0,536 & 0,757 & 0,363 & 0,357 & 0,215 & 0,639 & 0,330 & 0,359 \\
\hline PCC11 & 0,493 & 0,181 & 0,146 & 0,228 & 0,261 & 0,158 & 0,536 & 0,936 & 0,363 & 0,357 & 0,215 & 0,703 & 0,330 & 0,359 \\
\hline $\mathrm{PCC} 12$ & 0,609 & 0,115 & 0,208 & 0,114 & 0,227 & 0,181 & 0,505 & 0,829 & 0,520 & 0,371 & 0,146 & 0,758 & 0,345 & 0,322 \\
\hline PCC12 & 0,609 & 0,115 & 0,208 & 0,114 & 0,227 & 0,181 & 0,505 & 0,948 & 0,520 & 0,371 & 0,146 & 0,761 & 0,345 & 0,322 \\
\hline $\mathrm{PCC} 13$ & 0,626 & 0,184 & 0,197 & 0,223 & 0,233 & 0,127 & 0,487 & 0,814 & 0,411 & 0,305 & 0,178 & 0,733 & 0,337 & 0,405 \\
\hline PCC13 & 0,626 & 0,184 & 0,197 & 0,223 & 0,233 & 0,127 & 0,487 & 0,962 & 0,411 & 0,305 & 0,178 & 0,750 & 0,337 & 0,405 \\
\hline PCC2 & 0,547 & 0,121 & 0,239 & 0,135 & 0,262 & 0,171 & 0,255 & 0,434 & 0,832 & 0,239 & 0,120 & 0,746 & 0,242 & 0,331 \\
\hline PCC2 & 0,547 & 0,121 & 0,239 & 0,135 & 0,262 & 0,171 & 0,255 & 0,434 & 0,969 & 0,239 & 0,120 & 0,683 & 0,242 & 0,331 \\
\hline $\mathrm{PCC}_{3}$ & 0,536 & 0,151 & 0,244 & 0,171 & 0,288 & 0,185 & 0,293 & 0,446 & 0,858 & 0,304 & 0,112 & 0,734 & 0,247 & 0,370 \\
\hline $\mathrm{PCC} 3$ & 0,536 & 0,151 & 0,244 & 0,171 & 0,288 & 0,185 & 0,293 & 0,446 & 0,943 & 0,304 & 0,112 & 0,700 & 0,247 & 0,370 \\
\hline $\mathrm{PCC} 4$ & 0,791 & 0,108 & 0,281 & 0,083 & 0,213 & 0,118 & 0,280 & 0,545 & 0,602 & 0,234 & 0,201 & 0,762 & 0,331 & 0,297 \\
\hline $\mathrm{PCC} 4$ & 0,765 & 0,108 & 0,281 & 0,083 & 0,213 & 0,118 & 0,280 & 0,545 & 0,602 & 0,234 & 0,201 & 0,685 & 0,331 & 0,297 \\
\hline $\mathrm{PCC} 5$ & 0,822 & 0,153 & 0,329 & 0,145 & 0,213 & 0,092 & 0,313 & 0,583 & 0,506 & 0,214 & 0,110 & 0,842 & 0,376 & 0,294 \\
\hline $\mathrm{PCC} 5$ & 0,955 & 0,153 & 0,329 & 0,145 & 0,213 & 0,092 & 0,313 & 0,583 & 0,506 & 0,214 & 0,110 & 0,735 & 0,376 & 0,294 \\
\hline PCC6 & 0,841 & 0,173 & 0,319 & 0,148 & 0,231 & 0,097 & 0,320 & 0,589 & 0,524 & 0,238 & 0,117 & 0,859 & 0,367 & 0,307 \\
\hline PCC6 & 0,973 & 0,173 & 0,319 & 0,148 & 0,231 & 0,097 & 0,320 & 0,589 & 0,524 & 0,238 & 0,117 & 0,752 & 0,367 & 0,307 \\
\hline PCC7 & 0,844 & 0,174 & 0,310 & 0,157 & 0,250 & 0,101 & 0,322 & 0,591 & 0,523 & 0,249 & 0,125 & 0,859 & 0,367 & 0,301 \\
\hline PCC7 & 0,972 & 0,174 & 0,310 & 0,157 & 0,250 & 0,101 & 0,322 & 0,591 & 0,523 & 0,249 & 0,125 & 0,755 & 0,367 & 0,301 \\
\hline PCC8 & 0,796 & 0,141 & 0,267 & 0,130 & 0,298 & 0,104 & 0,302 & 0,603 & 0,513 & 0,270 & 0,148 & 0,765 & 0,315 & 0,275 \\
\hline PCC8 & 0,801 & 0,141 & 0,267 & 0,130 & 0,298 & 0,104 & 0,302 & 0,603 & 0,513 & 0,270 & 0,148 & 0,697 & 0,315 & 0,275 \\
\hline PCC9 & 0,804 & 0,218 & 0,203 & 0,135 & 0,271 & 0,176 & 0,303 & 0,623 & 0,528 & 0,224 & 0,117 & 0,792 & 0,284 & 0,292 \\
\hline PCC9 & 0,829 & 0,218 & 0,203 & 0,135 & 0,271 & 0,176 & 0,303 & 0,623 & 0,528 & 0,224 & 0,117 & 0,706 & 0,284 & 0,292 \\
\hline PROUSO1 & 0,295 & 0,209 & 0,294 & 0,479 & 0,437 & 0,253 & 0,364 & 0,388 & 0,349 & 0,286 & 0,164 & 0,382 & 0,340 & 0,872 \\
\hline PROUSO2 & 0,287 & 0,039 & 0,146 & 0,252 & 0,209 & 0,156 & 0,360 & 0,381 & 0,298 & 0,240 & 0,224 & 0,358 & 0,462 & 0,717 \\
\hline PROUSO3 & 0,296 & 0,163 & 0,232 & 0,363 & 0,312 & 0,233 & 0,381 & 0,362 & 0,274 & 0,223 & 0,194 & 0,350 & 0,436 & 0,789 \\
\hline $\mathrm{PROUSO}_{4}$ & 0,221 & 0,221 & 0,306 & 0,335 & 0,355 & 0,282 & 0,238 & 0,238 & 0,290 & 0,157 & 0,072 & 0,283 & 0,268 & 0,662 \\
\hline
\end{tabular}


Tabela 7. Critérios HTMT na amostra (Brasil)

\begin{tabular}{|l|r|r|r|r|r|r|r|l|l|l|l|l|l|l|}
\hline & $\begin{array}{l}\text { Apoio } \\
\text { ao anf. }\end{array}$ & $\begin{array}{l}\text { Con } \\
\text { Facil. }\end{array}$ & Confi & Econ. & $\begin{array}{l}\text { Exp. } \\
\text { Des. }\end{array}$ & $\begin{array}{l}\text { Exp. } \\
\text { Esf. }\end{array}$ & $\begin{array}{l}\text { Exp. } \\
\text { Vinc. }\end{array}$ & $\begin{array}{l}\text { Exp. } \\
\text { Cocri } \\
\text { a }\end{array}$ & $\begin{array}{l}\text { Feed } \\
\text { backs }\end{array}$ & $\begin{array}{l}\text { Grau } \\
\text { Ident. }\end{array}$ & $\begin{array}{l}\text { Inf. } \\
\text { Social }\end{array}$ & $\begin{array}{l}\text { Perc. } \\
\text { Cocri } \\
\text { a }\end{array}$ & $\begin{array}{l}\text { Per. } \\
\text { Antiin } \\
\text { dustria }\end{array}$ & $\begin{array}{l}\text { Prop } \\
\text { uso }\end{array}$ \\
\hline Apoio ao a. & & & & & & & & & & & & & & \\
\hline Cond. Facil. & 0,198 & & & & & & & & & & & & & \\
\hline Confianca & 0,35 & 0,2 & & & & & & & & & & & & \\
\hline Econ. Cust & 0,157 & 0,2 & 0,1 & & & & & & & & & & & \\
\hline Exp. Des. & 0,301 & 0,5 & 0,3 & 0,35 & & & & & & & & & & \\
\hline Exp. Esf. & 0,141 & 0,6 & 0,2 & 0,25 & 0,7 & & & & & & & & & \\
\hline Exp. Vinc. & 0,376 & 0,2 & 0,2 & 0,38 & 0,3 & 0,23 & & & & & & & & \\
\hline Exp. Cocria & 0,722 & 0,2 & 0,2 & 0,23 & 0,3 & 0,19 & 0,635 & & & & & & & \\
\hline Feedbacks & 0,651 & 0,2 & 0,3 & 0,15 & 0,33 & 0,21 & 0,324 & 0,53 & & & & & & \\
\hline Grau Ident. & 0,287 & 0,3 & 0,1 & 0,22 & 0,29 & 0,25 & 0,537 & 0,43 & 0,31 & & & & & \\
\hline Inf. Social & 0,158 & 0,1 & 0,1 & 0,16 & 0,17 & 0,09 & 0,148 & 0,21 & 0,13 & 0,35 & & & & \\
\hline Perc. Cocr & 0,995 & 0,2 & 0,3 & 0,2 & 0,36 & 0,2 & 0,48 & 0,88 & 0,88 & 0,37 & 0,18 & & & \\
\hline Per. Antii & 0,411 & 0,1 & 0,2 & 0,3 & 0,21 & 0,08 & 0,409 & 0,41 & 0,27 & 0,36 & 0,32 & 0,42 & & \\
\hline Prop uso & 0,363 & 0,2 & 0,3 & 0,47 & 0,43 & 0,3 & 0,442 & 0,45 & 0,4 & 0,3 & 0,22 & 0,45 & 0,496 & \\
\hline
\end{tabular}

\section{- Avaliação do modelo de mensuração (Portugal)}

A Figura 5 apresenta o modelo de mensuração referente à amostra de Portugal. 
Figura 5. Modelo de mensuração do Airbnb (Portugal)

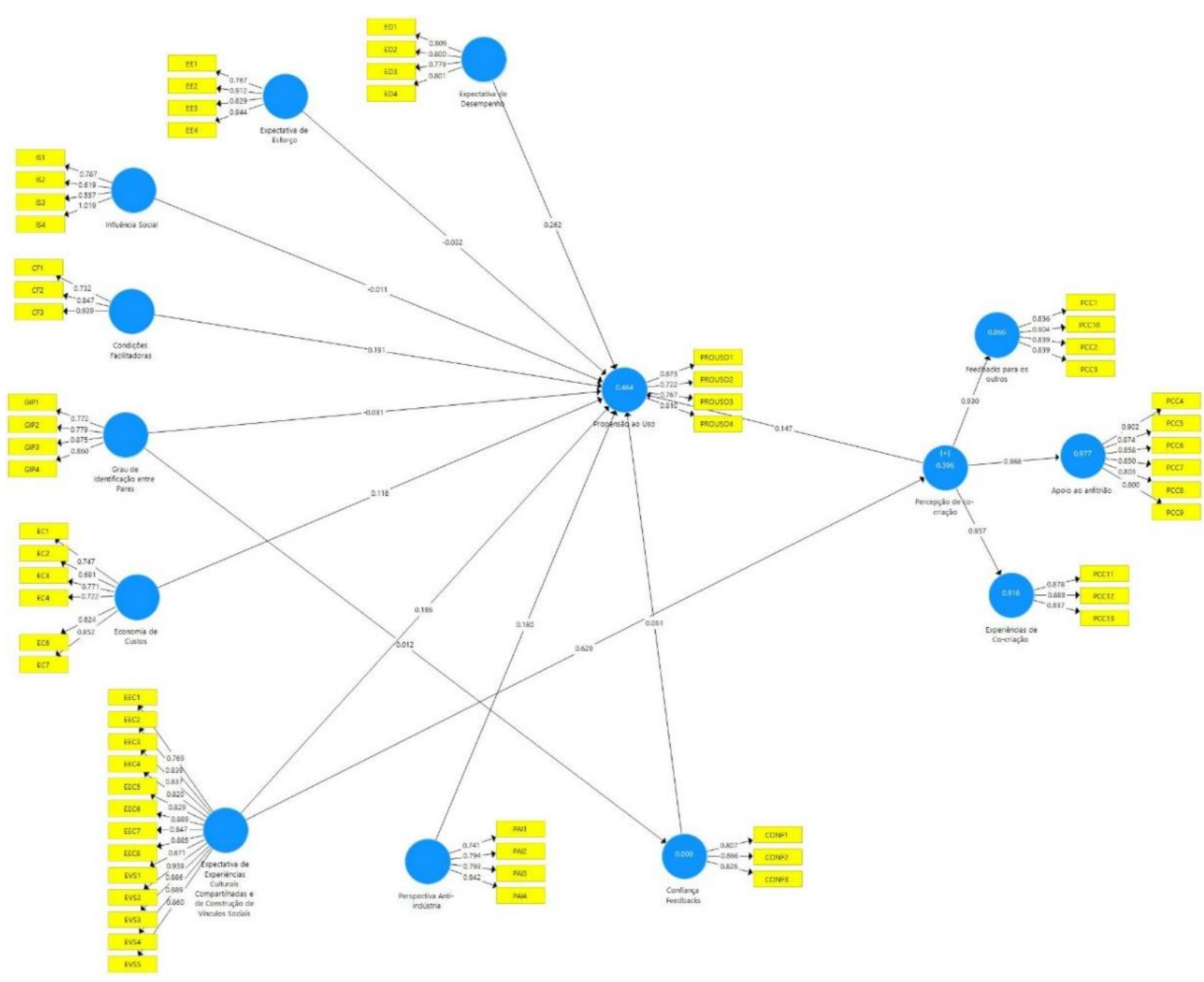

Fonte: Elaborada pelos autores, saída SMART PLS (2019).

\section{- Confiabilidade simples e confiabilidade composta}

A análise da confiabilidade foi realizada a partir dos valores do alpha de Cronbach e da confiabilidade composta. Todos os valores estiveram acima de 0,7 e foram, portanto, satisfatórios. A Tabela 8 indica estes valores. 
Tabela 8. Confiabilidade simples e composta do modelo de mensuração da amostra (Portugal)

\begin{tabular}{|l|r|r|}
\hline \multicolumn{1}{|c|}{ Construto } & \multicolumn{2}{c|}{ Airbnb Portugal } \\
\hline & $\begin{array}{c}\text { Confiabilidade } \\
\text { Simples }\end{array}$ & Confiabilidade Composta \\
\hline Condições Facilitadoras & 0,882 & 0,880 \\
\hline Confiança baseada nos Feedbacks & 0,872 & 0,872 \\
\hline Economia de Custos & 0,901 & 0,896 \\
\hline Expectativa de Desempenho & 0,875 & 0,875 \\
\hline Expectativa de Esforço & 0,926 & 0,925 \\
\hline Expectativa de Experiências Culturais Compartilhadas & 0,974 & 0,973 \\
e de Construção de Vínculos Sociais & 0,892 & 0,893 \\
\hline Grau de Identificação entre Pares & 0,857 & 0,844 \\
\hline Influência Social & 0,955 & 0,955 \\
\hline Percepção de cocriação & 0,870 & 0,871 \\
\hline Perspectiva Anti-indústria & 0,873 & 0,873 \\
\hline Propensão ao Uso & & \\
\hline
\end{tabular}

\section{- Validade convergente}

A análise da validade convergente da amostra do Airbnb Portugal mostrou que tanto os valores da AVE quanto os valores das cargas externas estiveram de acordo com os parâmetros indicados por Hair et al. (2014b), conforme pode ser observado nas Tabelas 9, 10 e 11.

Tabela 9. Variância média extraída (AVE) da amostra do Airbnb (Portugal)

\begin{tabular}{|l|r|}
\hline \multicolumn{1}{|c|}{ Construto } & \multicolumn{1}{c|}{$\begin{array}{c}\text { Airbnb } \\
\text { Portugal }\end{array}$} \\
\hline & \multicolumn{1}{|c|}{ AVE } \\
\hline Condições facilitadoras & 0,712 \\
\hline Confiança baseada nos Feedbacks & 0,695 \\
\hline Economia de Custos & 0,590 \\
\hline Expectativa de Desempenho & 0,636 \\
\hline Expectativa de Esforço & 0,757 \\
\hline Expectativa de Experiências Culturais Compartilhadas e de Construção de Vínculos & 0,738 \\
\hline Sociais & 0,677 \\
\hline Grau de Identificação entre Pares & 0,588 \\
\hline Influência Social & 0,619 \\
\hline Percepção de cocriação & 0,629 \\
\hline Perspectiva Anti-indústria & 0,632 \\
\hline Propensão ao Uso & \\
\hline
\end{tabular}


Tabela 10. Avaliação das cargas externas dos construtos de primera ordem da amostra (Portugal)

\begin{tabular}{|c|c|c|}
\hline Construto & Indicadores & Outer Loadings \\
\hline \multirow{3}{*}{ Condições Facilitadoras } & CF1 & 0,732 \\
\hline & $\mathrm{CF}_{2}$ & 0,847 \\
\hline & $\mathrm{CF}_{3}$ & 0,939 \\
\hline \multirow{3}{*}{ Confiança baseada nos Feedbacks } & CONF1 & 0,807 \\
\hline & CONF2 & 0,866 \\
\hline & CONF3 & 0,826 \\
\hline \multirow{6}{*}{ Economia de Custos } & EC1 & 0,747 \\
\hline & $\mathrm{EC2}$ & 0,681 \\
\hline & $\mathrm{EC} 3$ & 0,771 \\
\hline & EC4 & 0,722 \\
\hline & EC6 & 0,824 \\
\hline & EC7 & 0,852 \\
\hline \multirow{4}{*}{ Expectativa de Desempenho } & ED1 & 0,809 \\
\hline & ED2 & 0,800 \\
\hline & ED3 & 0,779 \\
\hline & ED4 & 0,801 \\
\hline \multirow{4}{*}{ Expectativa de Esforço } & EE1 & 0,787 \\
\hline & EE2 & 0,912 \\
\hline & EE3 & 0,829 \\
\hline & EE4 & 0,944 \\
\hline \multirow{13}{*}{$\begin{array}{l}\text { Expectativa de Experiências Culturais } \\
\text { Compartilhadas e de Vínculos Sociais }\end{array}$} & EEC1 & 0,769 \\
\hline & $\mathrm{EEC2}$ & 0,839 \\
\hline & $\mathrm{EEC} 3$ & 0,837 \\
\hline & $\mathrm{EEC}_{4}$ & 0,820 \\
\hline & EEC5 & 0,829 \\
\hline & EEC6 & 0,889 \\
\hline & EEC7 & 0,847 \\
\hline & EEC8 & 0,885 \\
\hline & EVS1 & 0,871 \\
\hline & EVS2 & 0,939 \\
\hline & EVS3 & 0,886 \\
\hline & EVS4 & 0,889 \\
\hline & EVS5 & 0,860 \\
\hline \multirow{4}{*}{ Grau de Identificação entre Pares } & GIP1 & 0,772 \\
\hline & GIP2 & 0,779 \\
\hline & $\mathrm{GIP}_{3}$ & 0,875 \\
\hline & GIP4 & 0,860 \\
\hline \multirow{4}{*}{ Influência Social } & IS1 & 0,787 \\
\hline & IS2 & 0,619 \\
\hline & IS3 & 0,557 \\
\hline & IS4 & 1,019 \\
\hline \multirow{4}{*}{ Perspectiva Anti-indústria } & PAl1 & 0,741 \\
\hline & $\mathrm{PAl} 2$ & 0,794 \\
\hline & PAl3 & 0,793 \\
\hline & $\mathrm{PAl} 4$ & 0,842 \\
\hline \multirow{4}{*}{ Propensão ao Uso } & PROUSO1 & 0,873 \\
\hline & PROUSO2 & 0,722 \\
\hline & $\mathrm{PROUSO}_{3}$ & 0,767 \\
\hline & PROUSO4 & 0,810 \\
\hline
\end{tabular}


Tabela 11. Avaliação das cargas externas do construto de segunda ordem perceção de cocriação e de suas dimensões na amostra (Portugal)

\begin{tabular}{|c|c|c|c|c|c|}
\hline $\begin{array}{l}\text { Construto } \\
\text { de } \\
\text { segunda } \\
\text { ordem }\end{array}$ & Indicadores & Outer Loadings & $\begin{array}{l}\text { Dimensões do } \\
\text { construto de } \\
\text { segunda ordem }\end{array}$ & Indicadores & $\begin{array}{l}\text { Outer } \\
\text { Loadings }\end{array}$ \\
\hline \multirow{13}{*}{$\begin{array}{c}\text { Percepção } \\
\text { de } \\
\text { Cocriação }\end{array}$} & PCC1 & 0,7581174 & \multirow{4}{*}{$\begin{array}{c}\text { Feedback para } \\
\text { os outros }\end{array}$} & PCC1 & 0,8355649 \\
\hline & PCC2 & 0,7649083 & & $\mathrm{PCC} 2$ & 0,8392423 \\
\hline & $\mathrm{PCC}_{3}$ & 0,7558521 & & $\mathrm{PCC}_{3}$ & 0,8391184 \\
\hline & PCC10 & 0,7943259 & & PCC10 & 0,9037214 \\
\hline & $\mathrm{PCC}_{4}$ & 0,8124371 & \multirow{6}{*}{$\begin{array}{l}\text { Apoio ao } \\
\text { anfitrião }\end{array}$} & $\mathrm{PCC}_{4}$ & 0,9018265 \\
\hline & PCC5 & 0,8035595 & & PCC5 & 0,8738774 \\
\hline & PCC6 & 0,7904374 & & PCC6 & 0,8575288 \\
\hline & PCC7 & 0,7836382 & & PCC7 & 0,8499737 \\
\hline & PCC8 & 0,7291875 & & PCC8 & 0,8031616 \\
\hline & PCC9 & 0,7319281 & & PCC9 & 0,7995023 \\
\hline & PCC11 & 0,8386561 & \multirow{3}{*}{$\begin{array}{c}\text { Experiências de } \\
\text { cocriação }\end{array}$} & PCC11 & 0,8780894 \\
\hline & PCC12 & 0,8473829 & & PCC12 & 0,8884813 \\
\hline & PCC13 & 0,8063869 & & PCC13 & 0,8374256 \\
\hline
\end{tabular}

\section{- Validade discriminante}

$\mathrm{Na}$ análise da validade discriminante, foram consideradas as cargas cruzadas, o critério de Fornell-Larcker e HTMT. Os resultados foram considerados satisfatórios, como pode ser visto nas Tabelas 12, 13 e 14.

Tabela 12. Validade discriminante - Critério Fornell na amostra (Portugal)

\begin{tabular}{|l|r|r|r|r|l|l|l|l|l|l|l|l|l|l|}
\hline & $\begin{array}{l}\text { Apoio } \\
\text { ao anf. }\end{array}$ & $\begin{array}{l}\text { ld. } \\
\text { Facil. }\end{array}$ & Confi & Econ. & $\begin{array}{l}\text { Exp. } \\
\text { Des. }\end{array}$ & $\begin{array}{l}\text { Exp. } \\
\text { Esf. }\end{array}$ & $\begin{array}{l}\text { Exp. } \\
\text { Vinc. }\end{array}$ & $\begin{array}{l}\text { Exp. } \\
\text { Cocri } \\
\text { a }\end{array}$ & $\begin{array}{l}\text { Feedb } \\
\text { acks }\end{array}$ & $\begin{array}{l}\text { Grau } \\
\text { Ident. }\end{array}$ & $\begin{array}{l}\text { Inf. } \\
\text { Social }\end{array}$ & $\begin{array}{l}\text { Perc. } \\
\text { Cocria }\end{array}$ & $\begin{array}{l}\text { Per. } \\
\text { Antiin } \\
\text { dustri }\end{array}$ & $\begin{array}{l}\text { Prop } \\
\text { uso }\end{array}$ \\
\hline Apoio anf. & 0,848 & & & & & & & & & & & & & \\
\hline Cond. Facil. & 0,192 & 0,8 & & & & & & & & & & & & \\
\hline Confianca & 0,369 & 0,4 & 0,83 & & & & & & & & & & & \\
\hline Econ. Cust & 0,37 & 0,2 & 0,31 & 0,77 & & & & & & & & & & \\
\hline Exp. Des. & 0,183 & 0,4 & 0,24 & 0,46 & 0,8 & & & & & & & & & \\
\hline Exp. Esf. & 0,221 & 0,5 & 0,2 & 0,34 & 0,63 & 0,87 & & & & & & & & \\
\hline Exp. Vinc. & 0,536 & 0,1 & 0,37 & 0,5 & 0,24 & 0,22 & 0,86 & & & & & & & \\
\hline Exp. Cocria & 0,828 & 0,1 & 0,35 & 0,42 & 0,22 & 0,223 & 0,68 & 0,87 & & & & & & \\
\hline Feedbacks & 0,745 & 0,1 & 0,4 & 0,36 & 0,19 & 0,203 & 0,56 & 0,77 & 0,86 & & & & & \\
\hline Grau Ident. & 0,277 & 0,1 & -0 & 0,21 & 0,17 & 0,164 & 0,39 & 0,32 & 0,33 & 0,82 & & & & \\
\hline Inf. Social & 0,196 & 0 & 0 & 0,11 & 0,11 & 0,121 & 0,27 & 0,17 & 0,18 & 0,44 & 0,77 & & & \\
\hline Perc. Cocria & 0,988 & 0,2 & 0,41 & 0,41 & 0,21 & 0,235 & 0,63 & 0,96 & 0,93 & 0,33 & 0,2 & 0,787 & & \\
\hline Per. Antiindus & 0,283 & $-0,1$ & -0 & 0,18 & 0,2 & 0,107 & 0,3 & 0,26 & 0,27 & 0,47 & 0,43 & 0,299 & 0,79 & \\
\hline Prop uso & 0,438 & 0,4 & 0,35 & 0,47 & 0,49 & 0,372 & 0,47 & 0,47 & 0,36 & 0,25 & 0,17 & 0,458 & 0,32 & 0,795 \\
\hline
\end{tabular}


Tabela 13. Cargas cruzadas na amostra (Portugal)

\begin{tabular}{|c|c|c|c|c|c|c|c|c|c|c|c|c|c|c|}
\hline & $\begin{array}{l}\text { Apoio } \\
\text { ao } \\
\text { anf. }\end{array}$ & $\begin{array}{l}\text { Cond. } \\
\text { Facil. }\end{array}$ & $\begin{array}{l}\text { Conf. } \\
\text { Feed } \\
\text { backs }\end{array}$ & $\begin{array}{l}\text { Econ. } \\
\text { Cust. }\end{array}$ & $\begin{array}{l}\text { Exp. } \\
\text { Des. }\end{array}$ & $\begin{array}{l}\text { Exp. } \\
\text { Esf. }\end{array}$ & $\begin{array}{l}\text { Exp. } \\
\text { Const } \\
\text { Vínc. } \\
\text { Sociais }\end{array}$ & $\begin{array}{l}\text { Exp. } \\
\text { Cocria } \\
\text { ção }\end{array}$ & $\begin{array}{l}\text { Feed } \\
\text { backs } \\
\text { para } \\
\text { os ou } \\
\text { tros }\end{array}$ & $\begin{array}{l}\text { Grau } \\
\text { Ident. } \\
\text { Pares }\end{array}$ & $\begin{array}{l}\text { Inf. } \\
\text { Soc. }\end{array}$ & $\begin{array}{l}\text { Perc } \\
\text { Cocria } \\
\text { ção }\end{array}$ & \begin{tabular}{|l|} 
Per. \\
Anti- \\
Indús \\
tria
\end{tabular} & $\begin{array}{l}\text { Pro } \\
\text { Uso }\end{array}$ \\
\hline CF1 & 0,120 & 0,732 & 0,265 & 0,180 & 0,320 & 0,413 & $-0,007$ & 0,023 & 0,059 & 0,005 & 0,022 & 0,084 & $-0,115$ & 0,244 \\
\hline CF2 & 0,166 & 0,847 & 0,310 & 0,167 & 0,340 & 0,413 & 0,095 & 0,107 & 0,119 & 0,073 & 0,036 & 0,149 & 0,028 & 0,339 \\
\hline $\mathrm{CF}_{3}$ & 0,194 & 0,939 & 0,357 & 0,214 & 0,350 & 0,479 & 0,113 & 0,149 & 0,118 & 0,069 & $-0,017$ & 0,174 & $-0,077$ & 0,310 \\
\hline CONF1 & 0,306 & 0,338 & 0,807 & 0,279 & 0,216 & 0,189 & 0,242 & 0,263 & 0,296 & $-0,040$ & 0,002 & 0,318 & $-0,021$ &, 304 \\
\hline CONF2 & 0,318 & 0,366 & 0,866 & 0,257 & 0,214 & 0,183 & 0,311 & 0,294 & 0,354 & $-0,024$ & $-0,034$ & 0,351 & $-0,019$ & 0,272 \\
\hline CONF3 & 0,298 & 0,221 & 0,826 & 0,246 & 0,165 & 0,134 & 0,360 & 0,327 & 0,354 & 0,034 & 0,030 & 0,350 & $-0,025$ & 0,295 \\
\hline EC1 & 0,289 & 0,179 & 0,285 & 0,747 & 0,366 & 0,251 & 0,353 & 0,308 & 0,256 & 0,077 & 0,007 & 0,308 & 0,061 & 0,407 \\
\hline EC2 & 0,255 & 0,180 & 0,279 & 0,681 & 0,343 & 0,215 & 0,325 & 273 & 0,239 & 0,059 & 014 & 277 & 0,061 & 368 \\
\hline $\mathrm{EC}_{3}$ & 0,286 & 0,168 & 0,284 & 0,771 & 0,380 & 0,274 & 0,399 &, 321 & 0,258 & 0,096 & 0,076 & 311 & 0,065 & 376 \\
\hline EC4 & 0,228 & 0,215 & 0,220 & 0,722 & 0,375 & 0,321 & 0,349 & 0,285 & 0,242 & 0,151 & 0,037 & 0,267 & 0,133 & 0,339 \\
\hline EC6 & 337 & & 0,158 & 0,824 & 0,317 & & & 0,383 & 0,376 & 281 & 193 & 391 & 0,258 & 298 \\
\hline EC7 & 0,305 & 0,177 & 0,232 & 0,852 & 0,358 & 0,313 & 0,441 & 0,351 & 0,288 & 0,274 & 146 & 0,338 & 0,238 & 386 \\
\hline ED1 & 0,126 & 0,407 & 0,237 & 0,309 & 0,809 & 0,503 & 0,183 & 0,135 & 0,154 & 0,129 & 076 & 0,149 & 0,204 & 406 \\
\hline ED2 & 119 & 0,329 & 0,226 & 0,395 & 0,800 & 0,458 & 0,176 & 0,179 & 175 & 157 & 060 & 164 & 0,193 & 395 \\
\hline ED3 & 0,155 & 0,232 & 0,108 & 0,402 & 0,779 & 0,491 & 0,173 & 0,183 & 0,126 & 0,200 & 0,165 & 0,167 & 0,170 & ,397 \\
\hline ED4 & 0,184 & 0,300 & 0,186 & 0,369 & 0,801 & & 0,227 & 0,201 & 0,138 & 065 & 040 &, 189 & 0,080 & 373 \\
\hline EE1 & 0,155 & 0,431 & 0,148 & 0,230 & 0,516 & 0,787 & 0,167 & 0,168 & 0,160 & 0,137 & 091 &, 173 & 0,046 & 297 \\
\hline EE2 & 0,230 & 0,453 & 0,166 & 0,321 & 0,524 & 0,912 & 0,220 & 0,248 & 0,201 & 0,136 & 0,094 & 0,245 & 0,099 & 0,365 \\
\hline EE3 & 0,184 & 0,429 & 0,173 & 0,281 & 0,549 & 0,829 & 67 & 55 & 0,150 & 133 & 124 & 181 & 101 & 291 \\
\hline EE4 & 0,197 & 0,481 & 0,213 & 0,342 & 0,591 & 0,944 & 0,210 & 0,199 & 0,191 & 0,164 & 0,114 & 213 & 121 & 337 \\
\hline EEC1 & 0,438 & 0,100 & 0,332 & 0,365 & 0,121 & 0,145 & 0,769 & 0,520 & 0,440 & 0,268 & 236 & 0,499 &, 186 & 355 \\
\hline EEC2 & 0,436 & 0,110 & 0,288 & 0,383 & 0,180 & 0,217 & 0,839 & 0,566 & 0,488 & 0,353 & 200 & 0,526 & 0,284 & 0,412 \\
\hline $\mathrm{EEC} 3$ & 0,462 & 0,072 & 0,325 & 0,408 & 0,178 & 0,185 & 0,837 & 0,584 & 0,481 & 0,321 & 205 & 0,541 & 0,206 & 0,368 \\
\hline EEC4 & 0,403 & 0,037 & 0,266 & 0,430 & 0,207 & 0,171 & 0,820 & 0,556 & 0,481 & 319 & 234 & 505 & 0,260 & 412 \\
\hline EEC5 & 0,422 & 0,045 & 0,300 & 0,390 & 0,204 & 0,211 & 0,829 & 0,553 & 0,490 & 0,362 & 209 & 0,516 & 0,296 & 371 \\
\hline EEC6 & 0,461 & 0,064 & 0,342 & 0,414 & 0,217 & 0,191 & 0,889 & 0,617 & 0,526 & 0,324 & 226 & 0,564 & 0,288 & 412 \\
\hline EEC7 & & 0,085 & 99 & & 0,231 & & & & 0,461 & & 31 & & & 401 \\
\hline EEC 8 & 0,487 & 0,073 & 0,316 & 0,451 & 0,218 & 0,179 & 0,885 & 0,616 & 0,466 & 0,307 & 247 &, 557 & 0,288 &, 427 \\
\hline EVS1 & 0,468 & 0,023 & 0,328 & 0,474 & 0,223 & 0,182 & 0,871 & 0,590 & 0,469 & 0,338 & 245 & 0,541 & 0,233 & 0,417 \\
\hline EVS2 & 0,529 & 0,153 & 0,313 & 0,547 & 0,285 & 0,246 & 0,939 & 0,599 & 0,505 & 0,327 & 209 & 0,586 &, 273 &, 442 \\
\hline EVS3 & 0,510 & 0,098 & 0,353 & 0,435 & 0,168 & 0,177 & 0,886 & 0,615 & 0,483 & 0,362 & 0,222 & 0,574 & 0,205 &, 390 \\
\hline EVS4 & 471 & 0,100 & 0,355 & 0,421 & 0,179 & & 0,889 & 0,614 & 0,510 & 0,371 & 239 & 0,563 & & 400 \\
\hline EVS5 & 0,433 & $-0,017$ & 0,267 & 0,470 & 0,234 & 0,158 & 0,860 & 0,581 & 0,470 & 0,360 & 0,297 & 0,522 & 0,258 &, 440 \\
\hline GIP1 & 0,219 & 0,085 & $-0,011$ & 0,191 & 0,087 & 0,112 & 0,302 & 0,263 & 0,271 & 0,772 & 0,312 &, 266 & 0,332 & 0,239 \\
\hline GIP2 & 0,210 & 0,145 & $-0,001$ & 0,177 & 0,216 & 0,154 & 0,289 & 0,245 & 0,218 & 0,779 & 0,346 & 0,240 & 0,374 & 0,172 \\
\hline $\mathrm{GIP}_{3}$ & 0,234 & $-0,023$ & 0,003 & 0,172 & 0,120 & 0,114 & 0,351 & 0,287 & 0,294 & 0,875 & \begin{tabular}{|c|}
0,407 \\
\end{tabular} & 0,288 & 0,428 & 0,190 \\
\hline GIP4 & 0,247 & 0,007 & $-0,030$ & 155 & 0,145 & 0,161 & 0,323 & 0,263 & 0,291 & 0,860 & 0,384 & 0,287 & 416 & 0,208 \\
\hline IS1 & 0,160 & 0,038 & \begin{tabular}{|l|}
$-0,005$ \\
\end{tabular} & 0,045 & 0,097 & 0,094 & 0,136 & 0,084 & 0,146 & 0,375 & 0,787 & 0,149 & 0,392 & 0,132 \\
\hline IS2 & 0,177 & 0,066 & 0,064 & 0,074 & 0,071 & 0,102 & 0,230 & 0,134 & 0,115 & 0,197 & 0,619 & 0,160 &, 227 & 118 \\
\hline IS3 & 0,151 & 0,105 & 0,052 & 0,085 & 0,119 & 0,078 & 0,190 & 0,126 & 0,080 & 0,135 & 0,557 & 0,134 & 0,253 & 0,128 \\
\hline IS4 & 0,138 & 0,094 & $-0,067$ & 0,124 & 0,063 & 0,102 & 0,271 & 0,169 & 0,197 & 0,536 & 1,019 & 0,178 & 0,418 & 0,154 \\
\hline PAl1 & 0,178 & $-0,089$ & \begin{tabular}{|l|}
$-0,039$ \\
\end{tabular} & 0,168 & 0,239 & 0,042 & 0,187 & 0,151 & 0,183 & 0,369 & 0,365 & 0,188 & 0,741 & 0,223 \\
\hline PAl2 & 0,185 & $-0,187$ & $-0,090$ & 0,108 & 0,084 & $-0,024$ & 0,219 & 0,197 & 0,217 & 0,437 & 0,413 & 0,215 & 0,794 & 0,225 \\
\hline PAl3 & 0,263 & 0,008 & 0,024 & 0,152 & 0,138 & 0,131 & 0,265 & 0,216 & 0,233 & 0,333 & 0,293 & 0,264 & 0,793 & 0,273 \\
\hline PAl4 & 0,267 & 0,063 & 0,021 & 0,157 & 0,187 & 0,182 & 0,261 & 0,263 & 0,231 & 0,362 & 0,304 & 0,277 & 0,842 & 0,283 \\
\hline PCC1 & 0,619 & 0,155 & 0,321 & 0,324 & 0,170 & 0,168 & 0,486 & 0,608 & 0,836 & 0,256 & 0,167 & 0,775 & 0,257 & 0,329 \\
\hline PCC1 & 0,619 & 0,155 & 0,321 & 0,324 & 0,170 & 0,168 & 0,486 & 0,608 & 0,939 & 0,256 & 0,167 & 0,758 & 0,257 & 0,329 \\
\hline PCC10 & 0,697 & 0,124 & 0,364 & 0,307 & 0,155 & 0,219 & 0,489 & 0,744 & 0,904 & 0,288 & 0,122 & 0,831 & 0,187 & 0,308 \\
\hline PCC10 & 0,697 & 0,124 & 0,364 & 0,307 & 0,155 & 0,219 & 0,489 & 0,744 & 0,887 & 0,288 & 0,122 & 0,794 & 0,187 & 0,308 \\
\hline
\end{tabular}




\begin{tabular}{|c|c|c|c|c|c|c|c|c|c|c|c|c|c|c|}
\hline & $\begin{array}{l}\text { Apoio } \\
\text { ao } \\
\text { anf. }\end{array}$ & $\begin{array}{l}\text { Cond. } \\
\text { Facil. }\end{array}$ & $\begin{array}{l}\text { Conf. } \\
\text { Feed } \\
\text { backs }\end{array}$ & $\begin{array}{l}\text { Econ. } \\
\text { Cust. }\end{array}$ & $\begin{array}{l}\text { Exp. } \\
\text { Des. }\end{array}$ & $\begin{array}{l}\text { Exp. } \\
\text { Esf. }\end{array}$ & $\begin{array}{l}\text { Exp. } \\
\text { Const } \\
\text { Vínc. } \\
\text { Sociais }\end{array}$ & $\begin{array}{l}\text { Exp. } \\
\text { Cocria } \\
\text { ção }\end{array}$ & $\begin{array}{l}\text { Feed } \\
\text { backs } \\
\text { para } \\
\text { os ou } \\
\text { tros }\end{array}$ & $\begin{array}{l}\text { Grau } \\
\text { Ident. } \\
\text { Pares }\end{array}$ & $\begin{array}{l}\text { Inf. } \\
\text { Soc. }\end{array}$ & $\begin{array}{l}\text { Perc } \\
\text { Cocria } \\
\text { ção }\end{array}$ & $\begin{array}{l}\text { Per. } \\
\text { Anti- } \\
\text { Indús } \\
\text { tria }\end{array}$ & $\begin{array}{l}\text { Pro } \\
\text { Uso }\end{array}$ \\
\hline PCC11 & 0,720 & 0,106 & 0,319 & 0,375 & 0,200 & 0,184 & 0,585 & 0,878 & 0,694 & 0,261 & 0,123 &, 839 &, 237 & ,430 \\
\hline PCC11 & 0,720 & 0,106 & 0,319 & 0,375 & 0,200 & 0,184 & 0,585 & 0,962 & 0,694 & 0,261 & 0,123 & 0,839 & 0,237 & ,430 \\
\hline PCC12 & 0,724 & 0,068 & 0,277 & 0,344 & 0,192 & 0,214 & 0,627 & 0,888 & 0,699 & 0,335 & 0,188 & 0,844 & 0,250 & 392 \\
\hline PCC12 & 0,724 & 0,068 & 0,277 & 0,344 & 0,192 & 0,214 & 0,627 & 0,967 & 0,699 & 0,335 & 0,188 & 0,847 & 0,250 & 392 \\
\hline $\mathrm{PCC}_{13}$ & 0,712 & 0,128 & 0,327 & 0,373 & 0,176 & 0,182 & 0,560 & 0,837 & 0,621 & 0,239 & 0,121 & 0,810 & 0,196 &, 394 \\
\hline $\mathrm{PCC}_{13}$ & & 128 & 0,327 & 0,373 & 0,176 & 182 & 0,560 & 0,958 & 0,621 & 39 & 121 & 0,806 & 96 & 394 \\
\hline PCC2 & 0,618 & 0,075 & 0,348 & 0,297 & 0,155 & 0,158 & 0,473 & 0,636 & 0,839 & 0,266 & 0,147 & 0,796 & 0,272 & 293 \\
\hline PCC2 & 0,618 & 0,075 & 0,348 & 0,297 & 0,155 & 0,158 & 0,473 & 0,636 & 0,984 & 0,266 & 0,147 & 0,765 & 272 & 293 \\
\hline $\mathrm{PCC}_{3}$ & 611 & 0,053 & 0,341 & 0,312 & 0,156 & 0,145 & 0,472 & 0,654 & 0,839 & 309 & ,194 & 0,778 & 224 & 299 \\
\hline $\mathrm{PCC}_{3}$ & 611 & 0,053 & 0,341 & 0,312 & 0,156 & 0,145 & 0,472 & 0,654 & 0,925 &, 309 & 0,194 & 0,756 & 0,224 &, 299 \\
\hline $\mathrm{PCC}_{4}$ & 902 & 0,059 & 0,322 & 0,385 & 0,133 & 0,137 & 0,536 & 0,733 & 0,713 &, 308 & 0,186 & 0,845 & 0,293 & 0,387 \\
\hline $\mathrm{PCC}_{4}$ & 0,845 & 0,059 & 0,322 & 0,385 & 0,133 & 0,137 & 0,536 & 0,733 & 0,713 & 0,308 & 0,186 & 0,812 & 0,293 & 0,387 \\
\hline PCC5 & 0,874 & 0,189 & 0,343 & 0,315 & 0,161 & 0,212 & 0,467 & 0,740 & 0,617 & 0,230 & 0,170 & 0,873 & 0,241 & 0,370 \\
\hline $\mathrm{PCC}_{5}$ & 962 & 0,189 & & 0,315 & 0,161 & 0,212 & 0,467 & 0,740 & 0,617 & 230 & 170 & 0,804 & 0,241 & 370 \\
\hline PCC6 & 0,858 & 0,183 & 0,344 & 0,316 & 0,138 & 0,177 & 0,447 & 0,721 & 0,625 & 0,210 & 0,165 & 0,874 & 0,217 &, 349 \\
\hline PCC6 & 0,969 & 0,183 & 0,344 & 0,316 & 0,138 & 0,177 & 0,447 & 0,721 & 0,625 & 0,210 & 0,165 & 0,790 & 0,217 & 0,349 \\
\hline PCC7 & 0,850 & 0,166 & 0,317 & 0,299 & 0,119 & 0,163 & 0,439 & 0,719 & 0,627 & 0,227 & 0,180 & 0,874 & 0,234 & 0,334 \\
\hline $\mathrm{PCC}_{7}$ & 0,968 & 0,166 & 0,317 & 0,299 & 0,119 & 0,163 & 0,439 & 0,719 & 0,627 & 0,227 & 0,180 & 0,784 & 0,234 & 0,334 \\
\hline PCC8 & 0,803 & 0,145 & 0,238 & 0,308 & 0,171 & 0,201 & 0,444 & 0,650 & 0,619 & 0,224 & 0,177 & 0,774 & 0,241 & 0,376 \\
\hline PCC8 & 0,810 & 0,145 & 0,238 & 0,308 & 0,171 & 0,201 & 0,444 & 0,650 & 0,619 & 0,224 & 0,177 & 0,729 & 0,241 & 0,376 \\
\hline PCC9 & 0,800 & 0,246 & 0,309 & 0,256 & 0,217 & 0,243 & 0,387 & 0,646 & 0,587 & 0,204 & 0,117 & 0,787 & 0,211 & 0,416 \\
\hline PCC9 & & 0,246 & 0,309 & 0,256 & 0,217 & 0,243 & 0,387 & 0,646 & 0,587 & 0,204 & 0,117 & 0,732 & 0,211 & 0,416 \\
\hline PROUSO1 & 0,388 & 0,386 & 0,333 & 0,449 & 0,433 & 0,344 & 0,358 & 0,387 & 0,312 & 0,186 & 0,124 & 0,396 & 0,225 & 0,873 \\
\hline PROUSO2 & 0,337 & 0,116 & 0,240 & 0,309 & 0,322 & 0,192 & 0,388 & 0,358 & 0,277 & 0,229 & 0,184 & 0,352 & 0,325 & 0,722 \\
\hline $\mathrm{PROUSO}_{3}$ & 0,323 & 0,238 & 0,215 & 0,374 & 0,412 & 0,266 & 0,380 & 0,363 & 0,255 & 0,223 & 0,135 & 0,340 & 0,281 & 0,767 \\
\hline PROUSO4 & 0,341 & 0,362 & 0,309 & 0,353 & 0,394 & 0,367 & 0,376 & 0,378 & 0,296 & 0,150 & 0,113 & 0,366 & 0,193 & 0,810 \\
\hline
\end{tabular}

Tabela 14. Critério HTM na amostra (Portugal)

\begin{tabular}{|l|r|r|r|r|r|l|l|l|l|l|l|l|l|l|}
\hline & $\begin{array}{l}\text { Apoio ao } \\
\text { anf. }\end{array}$ & $\begin{array}{l}\text { Cond. } \\
\text { Facil. }\end{array}$ & Confi & Econ. & $\begin{array}{l}\text { Exp. } \\
\text { Des. }\end{array}$ & $\begin{array}{l}\text { Exp. } \\
\text { Esf. }\end{array}$ & $\begin{array}{l}\text { Exp. } \\
\text { Vinc. }\end{array}$ & $\begin{array}{l}\text { Exp. } \\
\text { Cocri } \\
\text { a }\end{array}$ & $\begin{array}{l}\text { Feed } \\
\text { backs }\end{array}$ & $\begin{array}{l}\text { Grau } \\
\text { Ident. }\end{array}$ & $\begin{array}{l}\text { Inf. } \\
\text { Social }\end{array}$ & $\begin{array}{l}\text { Perc. } \\
\text { Cocri } \\
\text { a }\end{array}$ & $\begin{array}{l}\text { Per. } \\
\text { Antiin } \\
\text { dustria }\end{array}$ & $\begin{array}{l}\text { Prop } \\
\text { uso }\end{array}$ \\
\hline Apoio ao a. & & & & & & & & & & & & & & \\
\hline Cond. Facil. & 0,192 & & & & & & & & & & & & & \\
\hline Confianca & 0,368 & 0,367 & & & & & & & & & & & & \\
\hline Econ. Cust & 0,364 & 0,221 & 0,3 & & & & & & & & & & \\
\hline Exp. Des. & 0,185 & 0,398 & 0,2 & 0,46 & & & & & & & & & & \\
\hline Exp. Esf. & 0,222 & 0,514 & 0,2 & 0,33 & 0,63 & & & & & & & & & \\
\hline Exp. Vinc. & 0,534 & 0,093 & 0,4 & 0,49 & 0,24 & 0,22 & & & & & & & & \\
\hline Exp. Cocria & 0,828 & 0,114 & 0,4 & 0,41 & 0,22 & 0,22 & 0,679 & & & & & & & \\
\hline Feedbacks & 0,743 & 0,116 & 0,4 & 0,36 & 0,19 & 0,2 & 0,56 & 0,77 & & & & & & \\
\hline Grau Ident. & 0,276 & 0,085 & 0 & 0,2 & 0,17 & 0,16 & 0,385 & 0,32 & 0,33 & & & & & \\
\hline Inf. Social & 0,202 & 0,104 & 0,1 & 0,11 & 0,12 & 0,12 & 0,267 & 0,17 & 0,17 & 0,4 & & & & \\
\hline Perc. Cocr & 0,99 & 0,163 & 0,4 & 0,41 & 0,21 & 0,23 & 0,627 & 0,95 & 0,93 & 0,33 & 0,2 & & & \\
\hline Per. Antii & 0,282 & 0,124 & 0,1 & 0,18 & 0,21 & 0,12 & 0,294 & 0,26 & 0,27 & 0,47 & 0,42 & 0,3 & & \\
\hline Prop uso & 0,438 & 0,345 & 0,3 & 0,46 & 0,49 & 0,37 & 0,471 & 0,47 & 0,36 & 0,25 & 0,17 & 0,46 & 0,322 & \\
\hline
\end{tabular}




\subsection{Avaliação dos modelos estruturais}

A avaliação do modelo estrutural envolve a avaliação da capacidade preditiva do modelo. Hair et al. (2014b) explicam que os estágios para a avaliação do modelo estrutural são: avaliar o tamanho e a significância dos coeficientes de caminho, examinar o coeficiente de determinação $\left(R^{2}\right)$, avaliar a relevância preditiva $\left(Q^{2}\right)$ e verificar o tamanho do efeito $f^{2}$.

4.7.1. Avaliação do modelo estrutural do Airbnb (Brasil): Na Tabela 15 são apresentados os coeficientes de caminho para a amostra do Airbnb (Brasil).

Tabela 15. Coeficiente de caminho da amostra do Airbnb (Brasil)

\begin{tabular}{|c|c|c|c|}
\hline Hipóteses & $\begin{array}{l}\text { Estatística } \\
\mathrm{T} \\
(|\mathrm{O} / \mathrm{STDEV}|)\end{array}$ & $\begin{array}{l}\text { Valores } \\
\text { de P }\end{array}$ & Significante \\
\hline Condições Facilitadoras -> Propensão ao Uso & 0,521 & 0,602 & $\begin{array}{l}\text { Não } \\
\text { significativa }\end{array}$ \\
\hline Confiança baseada nos Feedbacks -> Propensão ao Uso & 1,806 & 0,071 & $10 \%$ \\
\hline Economia de Custos -> Propensão ao Uso & 4,000 & 0,000 & $1 \%$ \\
\hline Expectativa de Desempenho -> Propensão ao Uso & 1,356 & 0,175 & $\begin{array}{l}\text { Não } \\
\text { significativa }\end{array}$ \\
\hline Expectativa de Esforço -> Propensão ao Uso & 1,015 & 0,310 & $\begin{array}{l}\text { Não } \\
\text { significativa }\end{array}$ \\
\hline $\begin{array}{l}\text { Expectativa de Experiências Culturais Compartilhadas e de } \\
\text { Construção de Vínculos Sociais -> Percepção de cocriação }\end{array}$ & 10,025 & 0,000 & $1 \%$ \\
\hline $\begin{array}{l}\text { Expectativa de Experiências Culturais Compartilhadas e de } \\
\text { Construção de Vínculos Sociais -> Propensão ao Uso }\end{array}$ & 1,533 & 0,125 & $\begin{array}{l}\text { Não } \\
\text { significativa }\end{array}$ \\
\hline $\begin{array}{l}\text { Grau de Identificação entre Pares -> Confiança baseada nos } \\
\text { Feedbacks }\end{array}$ & 1,633 & 0,103 & $10 \%$ \\
\hline Grau de Identificação entre Pares -> Propensão ao Uso & 0,496 & 0,620 & $\begin{array}{l}\text { Não } \\
\text { significativa }\end{array}$ \\
\hline Influência Social -> Propensão ao Uso & 0,531 & 0,595 & $\begin{array}{l}\text { Não } \\
\text { significativa }\end{array}$ \\
\hline Percepção de cocriação -> Apoio ao anfitrião & 112,079 & 0,000 & $1 \%$ \\
\hline Percepção de cocriação -> Experiências de Cocriação & 32,960 & 0,000 & $1 \%$ \\
\hline Percepção de cocriação -> Feedbacks para os outros & 36,724 & 0,000 & $1 \%$ \\
\hline Percepção de cocriação -> Propensão ao Uso & 2,193 & 0,028 & $5 \%$ \\
\hline Perspectiva Anti-Indústria -> Propensão ao Uso & 4,189 & 0,000 & $1 \%$ \\
\hline
\end{tabular}

Os coeficientes $\left(\mathrm{R}^{2}\right)$ de Apoio ao anfitrião, Experiências de Cocriação e Feedbacks para os outros são considerados substanciais. Os $\mathrm{R}^{2}$ de Confiança baseada nos Feedbacks e de Percepção de Cocriação foram considerados fracos. Já o coeficiente de determinação de Propensão ao Uso foi considerado moderado por ser próximo a 0,5. Isso pode ser observado na Tabela 16. 
Tabela 16. Coeficiente de determinação $\left(R^{2}\right)$ da amostra do Airbnb (Brasil)

\begin{tabular}{|l|r|r|}
\hline & R quadrado & R quadrado ajustado \\
\hline Apoio ao anfitrião & 0,993 & 0,993 \\
\hline Confiança Feedbacks & 0,008 & 0,006 \\
\hline Experiências de Cocriação & 0,789 & 0,789 \\
\hline Feedbacks para os outros & 0,763 & 0,763 \\
\hline Percepção de cocriação & 0,234 & 0,232 \\
\hline Propensão ao Uso & 0,470 & 0,457 \\
\hline
\end{tabular}

Os resultados do tamanho dos efeitos $\left(f^{2}\right)$ podem ser conferidos na Tabela 17.

Tabela 17. Tamanho dos efeitos $\left(\mathrm{f}^{2}\right)$ da amostra do Airbnb (Brasil)

\begin{tabular}{|l|r|l|}
\hline & $\mathbf{f}^{2}$ & Avaliação \\
\hline Condiçães Facilitadoras ->Propensão ao Uso & 0,001 & Muito pequeno \\
\hline Economia de Custos-> Propensão ao Uso & 0,091 & Pequeno \\
\hline Expectativa de Desempenho-> Propensão ao Uso & 0,014 & Muito pequeno \\
\hline Expectativa de Esforço->Propensão ao Uso & 0,005 & Muito pequeno \\
\hline $\begin{array}{l}\text { Expectativa de Experiências Culturais Compartilhadas e de Construção de } \\
\text { Vínculos Sociais ->Propensão ao Uso }\end{array}$ & 0,005 & \\
\hline $\begin{array}{l}\text { Expectativa de Experiências Culturais Compartilhadas e de Construção de } \\
\text { Vínculos Sociais -> Percepção de Cocriação }\end{array}$ & 0,305 & \\
\hline Confiança baseada em Feedbacks -> Propensão ao Uso & 0,025 & Pequeno \\
\hline Grau de Identificação entre Pares-> Confiança baseada em Feedbacks & 0,008 & Muito pequeno \\
\hline Grau de Identificação entre Pares->Propensão ao Uso & 0,001 & Muito pequeno \\
\hline Influência Social->Propensão ao Uso & 0,001 & Muito pequeno \\
\hline Percepção de Cocriação ->Apoio ao anfitrião & 148,752 & Grande \\
\hline Percepção de Cocriação -> Experiências de cocriação & 3,743 & Grande \\
\hline Percepção de Cocriação ->Feedback aos outros & 3,221 & Grande \\
\hline Percepção de Cocriação -> Propensão ao Uso & 0,024 & Pequeno \\
\hline Perspectiva Anti-Indústria->Propensão ao Uso & 0,084 & Pequeno \\
\hline
\end{tabular}

Os resultados da Tabela 18 indicam que a análise blindfolding foi positiva para todos os constructos endógenos, o que mostra que há relevância preditiva dos constructos exógenos em todos os casos. 
Tabela 18. Relevância preditiva $\left(\mathrm{Q}^{2}\right)$ da amostra do Airbnb (Brasil)

\begin{tabular}{|l|r|r|r|}
\hline & \multicolumn{1}{|l|}{ SSO } & \multicolumn{1}{l|}{ SSE } & Q $^{2}$ (=1-SSE/SSO) \\
\hline Apoio ao anfitrião & $2.694,000$ & $1.144,429$ & 0,575 \\
\hline Condiçães Facilitadoras & $1.347,000$ & $1.347,000$ & \\
\hline Confiança Feedbacks & $1.347,000$ & $1.342,025$ & 0,004 \\
\hline Economia de Custos & $2.694,000$ & $2.694,000$ & \\
\hline Expectativa de Desempenho & $1.796,000$ & $1.796,000$ & \\
\hline Expectativa de Esforço & $1.796,000$ & $1.796,000$ & \\
\hline $\begin{array}{l}\text { Expectativa de Experiências Culturais Compartilhadas e } \\
\text { de Construção de Vínculos Sociais }\end{array}$ & $5.837,000$ & $5.837,000$ & \\
\hline Experiências de Cocriação & $1.347,000$ & 748,183 & 0,445 \\
\hline Feedbacks para os outros & $1.796,000$ & 933,461 & 0,480 \\
\hline Grau de Identificação entre Pares & $1.796,000$ & $1.796,000$ & \\
\hline Influência Social & $1.796,000$ & $1.796,000$ & \\
\hline Percepção de cocriação & $5.837,000$ & $5.231,010$ & 0,104 \\
\hline Perspectiva Anti-Indústria & $1.796,000$ & $1.796,000$ & \\
\hline Propensão ao Uso & $1.796,000$ & $1.372,510$ & 0,236 \\
\hline
\end{tabular}

4.7.2. Avaliação do modelo estrutural do Airbnb (Portugal): A Tabela 19 apresenta os coeficientes de caminho da amostra do Airbnb (Portugal).

Tabela 19. Coeficiente de caminho da amostra do Airbnb (Portugal)

\begin{tabular}{|l|r|r|r|}
\hline Hipóteses & $\begin{array}{l}\text { Estatística T } \\
\text { (|O/STDEV })\end{array}$ & \multicolumn{1}{l|}{$\begin{array}{l}\text { Valores } \\
\text { de P }\end{array}$} & Significante \\
\hline Condições Facilitadoras -> Propensão ao Uso & 3,161 & 0,002 & $1 \%$ \\
\hline Confiança baseada nos Feedbacks -> Propensão ao Uso & 0,999 & 0,318 & Não significativa \\
\hline Economia de Custos -> Propensão ao Uso & 1,644 & 0,100 & $10 \%$ \\
\hline Expectativa de Desempenho -> Propensão ao Uso & 3,911 & 0,000 & $1 \%$ \\
\hline Expectativa de Esforço -> Propensão ao Uso & 0,515 & 0,606 & Não significativa \\
\hline $\begin{array}{l}\text { Expectativa de Experiências Culturais Compartilhadas e de } \\
\text { Construção de Vínculos Sociais -> Percepção de cocriação }\end{array}$ & 16,983 & 0,000 & \\
\hline $\begin{array}{l}\text { Expectativa de Experiências Culturais Compartilhadas e de } \\
\text { Construção de Vínculos Sociais -> Propensão ao Uso }\end{array}$ & 2,463 & 0,014 & \\
\hline Grau de Identificação entre Pares -> Confiança Feedbacks & 0,228 & 0,819 & Não significativa \\
\hline Grau de Identificação entre Pares -> Propensão ao Uso & 0,557 & 0,577 & Não significativa \\
\hline Influência Social -> Propensão ao Uso & 0,228 & 0,820 & Não significativa \\
\hline Percepção de cocriação -> Apoio ao anfitrião & 123,771 & 0,000 & \\
\hline Percepção de cocriação -> Experiências de Cocriação & 71,783 & 0,000 & $1 \%$ \\
\hline Percepção de cocriação -> Feedbacks para os outros & 56,967 & 0,000 & \\
\hline Percepção de cocriação -> Propensão ao Uso & 2,183 & 0,029 & \\
\hline Perspectiva Anti-Indústria -> Propensão ao Uso & 3,116 & 0,002 & $1 \%$ \\
\hline
\end{tabular}

Os coeficientes de determinação $\left(R^{2}\right)$ de Apoio ao Anfitrião, Experiências de Cocriação e Feedbacks para os outros foram considerados substanciais, vide Tabela 20. Os $R^{2}$ de Confiança baseada nos Feedbacks e de Percepção de Cocriação foram considerados fracos. 
Já o coeficiente de determinação de Propensão ao Uso foi considerado moderado por ser próximo a 0,5 . Neste sentido, os resultados da amostra do Airbnb (Portugal) foram semelhantes aos resultados da amostra do Airbnb (Brasil).

Tabela 20. Coeficiente de determinação $\left(R^{2}\right)$ da amostra do Airbnb (Portugal)

\begin{tabular}{|l|r|r|}
\hline & R quadrado & R quadrado ajustado \\
\hline Apoio ao anfitrião & 0,977 & 0,977 \\
\hline Confiança Feedbacks & 0,000 & $-0,002$ \\
\hline Experiências de Cocriação & 0,916 & 0,916 \\
\hline Feedbacks para os outros & 0,866 & 0,866 \\
\hline Percepção de cocriação & 0,396 & 0,395 \\
\hline Propensão ao Uso & 0,464 & 0,451 \\
\hline
\end{tabular}

Os resultados do tamanho do efeito da amostra do Airbnb (Portugal) podem ser vistos na Tabela 21.

Tabela 21. Tamanho dos efeitos $\left(\mathrm{f}^{2}\right)$ da amostra do Airbnb (Portugal)

\begin{tabular}{|l|r|l|}
\hline & $\mathbf{f}^{\mathbf{2}}$ & Avaliação \\
\hline Condiçães Facilitadoras ->Propensão ao Uso & 0,043 & Pequeno \\
\hline Economia de Custos-> Propensão ao Uso & 0,016 & Muito pequeno \\
\hline Expectativa de Desempenho-> Propensão ao Uso & 0,066 & Pequeno \\
\hline Expectativa de Esforço->Propensão ao Uso & 0,001 & Muito pequeno \\
\hline $\begin{array}{l}\text { Expectativa de Experiências Culturais Compartilhadas e de Construção } \\
\text { de Vínculos Sociais ->Propensão ao Uso }\end{array}$ & 0,031 & Pequeno \\
\hline $\begin{array}{l}\text { Expectativa de Experiências Culturais Compartilhadas e de Construção } \\
\text { de Vínculos Sociais -> Percepção de Cocriação }\end{array}$ & 0,656 & Grande \\
\hline Confiança baseada em Feedbacks -> Propensão ao Uso & 0,005 & Muito pequeno \\
\hline Grau de Identificação entre Pares-> Confiança baseada em Feedbacks & 0,000 & Muito pequeno \\
\hline Grau de Identificação entre Pares->Propensão ao Uso & 0,001 & Muito pequeno \\
\hline Influência Social->Propensão ao Uso & 0,000 & Muito pequeno \\
\hline Percepção de Cocriação ->Apoio ao anfitrião & 42,367 & Grande \\
\hline Percepção de Cocriação -> Experiências de cocriação & 10,910 & Grande \\
\hline Percepção de Cocriação ->Feedback aos outros & 6,453 & Grande \\
\hline Percepção de Cocriação -> Propensão ao Uso & 0,021 & Pequeno \\
\hline Perspectiva Anti-Indústria->Propensão ao Uso & 0,040 & Pequeno \\
\hline
\end{tabular}

Com exceção do constructo Confiança, todos os valores de Q2 foram acima de zero, o que indicou a relevância preditiva, como pode ser visto na Tabela 22. 
Tabela 22. Relevância preditiva $\left(\mathrm{Q}^{2}\right)$ da amostra do Airbnb (Portugal)

\begin{tabular}{|l|r|r|r|}
\hline & SSO & \multicolumn{1}{|l|}{ SSE } & Q $^{2}$ (=1-SSE/SSO) \\
\hline Apoio ao anfitrião & $2.556,000$ & 955,095 & 0,626 \\
\hline Condições Facilitadoras & $1.278,000$ & $1.278,000$ & 0,000 \\
\hline Confiança Feedbacks & $1.278,000$ & $1.278,504$ & \\
\hline Economia de Custos & $2.556,000$ & $2.556,000$ & \\
\hline Expectativa de Desempenho & $1.704,000$ & $1.704,000$ & \\
\hline Expectativa de Esforço & $1.704,000$ & $1.704,000$ & \\
\hline $\begin{array}{l}\text { Expectativa de Experiências Culturais Compartilhadas } \\
\text { e de Construção de Vínculos Sociais }\end{array}$ & $5.538,000$ & $5.538,000$ & \\
\hline Experiências de Cocriação & $1.278,000$ & 480,887 & \\
\hline Feedbacks para os outros & $1.704,000$ & 738,654 & 0,567 \\
\hline Grau de Identificação entre Pares & $1.704,000$ & $1.704,000$ & \\
\hline Influência Social & $1.704,000$ & $1.704,000$ & \\
\hline Percepção de cocriação & $5.538,000$ & $4.322,696$ & \\
\hline Perspectiva Anti-Indústria & $1.704,000$ & $1.704,000$ & 0,219 \\
\hline Propensão ao Uso & $1.704,000$ & $1.266,283$ & \\
\hline
\end{tabular}

\subsection{Análise multigrupos (PLS-MGA)}

Como pôde ser visto anteriormente durante todo o processo, a mensuração da invariância já foi estabelecida através das análises dos modelos de mensuração reflexiva. $O$ tipo do modelo trabalhado foi o factor model. A análise multigrupos ajuda a entender melhor se estas diferenças são estatisticamente significantes (Hair, Sarstedt, Ringle \& Gudergan, 2017). Tecnicamente, uma análise multigrupos testa a hipótese nula de que o coeficiente de caminho entre dois grupos não é significativamente diferente. A hipótese alternativa é a de que os coeficientes de caminho são diferentes.

O presente trabalho realizou uma análise multigrupos com as amostras do Brasil e de Portugal. Os resultados foram apresentados na Tabela 23. 
Tabela 23. Resultados da análise multigrupos

\begin{tabular}{|c|c|c|c|c|c|c|c|c|}
\hline & $\begin{array}{l}\text { Coeficientes } \\
\text { estruturais } \\
\text { Original } \\
\text { (Brasil) }\end{array}$ & $\begin{array}{l}\text { Coeficientes } \\
\text { estruturais } \\
\text { Original } \\
\text { (Portugal) }\end{array}$ & $\begin{array}{l}\text { Coeficientes } \\
\text { estruturais } \\
\text { média } \\
\text { (Brasil) }\end{array}$ & $\begin{array}{l}\text { Coeficientes } \\
\text { estruturais } \\
\text { média } \\
\text { (Portugal) }\end{array}$ & $\begin{array}{l}\text { valores } \\
\text { de t } \\
\text { (Brasil) }\end{array}$ & $\begin{array}{l}\text { valores de } \\
\text { t } \\
\text { (Portugal) }\end{array}$ & $\begin{array}{l}\text { valores } \\
\text { de p } \\
\text { (Brasil) }\end{array}$ & $\begin{array}{l}\text { valores de } \\
\text { p } \\
\text { (Portugal) }\end{array}$ \\
\hline $\begin{array}{l}\text { Condições } \\
\text { Facilitadoras -> } \\
\text { Propensão ao Uso }\end{array}$ & $-0,025$ & 0,162 & $-0,023$ & 0,160 & 0,540 & 3,344 & 0,589 & 0,001 \\
\hline $\begin{array}{l}\text { Confiança } \\
\text { Feedbacks -> } \\
\text { Propensão ao Uso }\end{array}$ & 0,119 & 0,065 & 0,122 & 0,069 & 2,102 & 1,416 & 0,036 & 0,157 \\
\hline $\begin{array}{l}\text { Economia de } \\
\text { Custos -> } \\
\text { Propensão ao Uso }\end{array}$ & 0,229 & 0,124 & 0,229 & 0,129 & 4,498 & 2,119 & 0,000 & 0,034 \\
\hline $\begin{array}{l}\text { Expectativa de } \\
\text { Desempenho -> } \\
\text { Propensão ao Uso }\end{array}$ & 0,117 & 0,217 & 0,117 & 0,212 & 1,988 & 4,230 & 0,047 & 0,000 \\
\hline $\begin{array}{l}\text { Expectativa de } \\
\text { Esforço -> } \\
\text { Propensão ao Uso }\end{array}$ & 0,077 & 0,009 & 0,078 & 0,012 & 1,515 & 0,192 & 0,130 & 0,848 \\
\hline $\begin{array}{l}\text { Expectativa de } \\
\text { Experiências } \\
\text { Culturais } \\
\text { Compartilhadas e } \\
\text { de Construção de } \\
\text { Vínculos Sociais -> } \\
\text { Percepção de } \\
\text { cocriação }\end{array}$ & 0,457 & 0,607 & 0,459 & 0,606 & 10,240 & 16,469 & 0,000 & 0,000 \\
\hline $\begin{array}{l}\text { Expectativa de } \\
\text { Experiências } \\
\text { Culturais } \\
\text { Compartilhadas e } \\
\text { de Construção de } \\
\text { Vínculos Sociais -> } \\
\text { Propensão ao Uso }\end{array}$ & 0,118 & 0,173 & 0,114 & 0,174 & 2,079 & 2,727 & 0,038 & 0,007 \\
\hline $\begin{array}{l}\text { Grau de } \\
\text { Identificação } \\
\text { entre Pares -> } \\
\text { Confiança } \\
\text { Feedbacks }\end{array}$ & 0,077 & $-0,011$ & 0,079 & $-0,012$ & 1,595 & 0,235 & 0,111 & 0,815 \\
\hline $\begin{array}{l}\text { Grau de } \\
\text { Identificação } \\
\text { entre Pares -> } \\
\text { Propensão ao Uso }\end{array}$ & $-0,013$ & $-0,005$ & $-0,013$ & $-0,006$ & 0,295 & 0,108 & 0,768 & 0,914 \\
\hline $\begin{array}{l}\text { Influência Social -> } \\
\text { Propensão ao Uso }\end{array}$ & 0,037 & $-0,007$ & 0,039 & $-0,001$ & 0,965 & 0,193 & 0,335 & 0,847 \\
\hline $\begin{array}{l}\text { Percepção de } \\
\text { cocriação -> Apoio } \\
\text { ao anfitrião }\end{array}$ & 0,924 & 0,936 & 0,924 & 0,936 & 77,509 & 91,801 & 0,000 & 0,000 \\
\hline $\begin{array}{l}\text { Percepção de } \\
\text { cocriação -> } \\
\text { Experiências de } \\
\text { Cocriação }\end{array}$ & 0,788 & 0,889 & 0,788 & 0,890 & 28,877 & 66,317 & 0,000 & 0,000 \\
\hline $\begin{array}{l}\text { Percepção de } \\
\text { cocriação -> } \\
\text { Feedbacks para os } \\
\text { outros }\end{array}$ & 0,805 & 0,870 & 0,806 & 0,870 & 34,607 & 48,551 & 0,000 & 0,000 \\
\hline $\begin{array}{l}\text { Percepção de } \\
\text { cocriação -> } \\
\text { Propensão ao Uso }\end{array}$ & 0,145 & 0,138 & 0,142 & 0,136 & 2,646 & 2,547 & 0,008 & 0,011 \\
\hline $\begin{array}{l}\text { Perspectiva Anti- } \\
\text { indústria -> } \\
\text { Propensão ao Uso }\end{array}$ & 0,208 & 0,147 & 0,210 & 0,146 & 4,592 & 3,390 & 0,000 & 0,001 \\
\hline
\end{tabular}


As conclusões acerca da análise multigrupos foram resumidas na Tabela 24.

Tabela 24. Conclusões da análise multigrupos

\begin{tabular}{|l|l|l|}
\hline Hipótese & Brasil & Portugal \\
\hline Condiçães Facilitadoras -> Propensão ao Uso & Não suportada & Suportada \\
\hline Confiança Feedbacks -> Propensão ao Uso & Suportada & Não suportada \\
\hline Economia de Custos -> Propensão ao Uso & Suportada & Suportada \\
\hline Expectativa de Desempenho -> Propensão ao Uso & Suportada & Suportada \\
\hline Expectativa de Esforço -> Propensão ao Uso & Não suportada & Não suportada \\
\hline $\begin{array}{l}\text { Expectativa de Experiências Culturais Compartilhadas e de } \\
\text { Construção de Vínculos Sociais -> Percepção de cocriação }\end{array}$ & Suportada & Suportada \\
\hline $\begin{array}{l}\text { Expectativa de Experiências Culturais Compartilhadas e de } \\
\text { Construção de Vínculos Sociais -> Propensão ao Uso }\end{array}$ & Suportada & Suportada \\
\hline Grau de Identificação entre Pares -> Confiança Feedbacks & Não suportada & Não suportada \\
\hline Grau de Identificação entre Pares -> Propensão ao Uso & Não suportada & Não suportada \\
\hline Influência Social -> Propensão ao Uso & Não suportada & Não suportada \\
\hline Percepção de cocriação -> Propensão ao Uso & Suportada & Suportada \\
\hline Perspectiva Anti-indústria -> Propensão ao Uso & Suportada & Suportada \\
\hline
\end{tabular}

\section{Discussão dos resultados}

O modelo teórico do Airbnb propôs doze hipóteses. Dez hipóteses tiveram o mesmo resultado tanto para o Brasil quanto para Portugal. As hipóteses de que a Economia de Custos, a Expectativa de Desempenho, a Expectativa de Experiências Culturais Compartilhadas e de Construção de Vínculos Sociais, a Percepção de Cocriação de Valor e a Perspectiva Anti-indústria têm relação direta com a Propensão de Uso foram suportadas.

A Expectativa de Experiências Culturais Compartilhadas e de Construção de Vínculos Sociais também foi suportada no estudo como um fator antecedente para a Propensão de Uso tanto na amostra do Airbnb do Brasil quanto na de Portugal. Tal achado apresenta sintonia com o que Liang et al. (2018) expuseram, baseados em estudos anteriores, que a busca de experiências de vida local corresponderia a um atrativo para os consumidores do Airbnb. Isso também tem relação com o que Heo (2016) apontou sobre o desejo de conexão com a comunidade local contribuir, de alguma forma, para a popularidade da economia compartilhada no turismo.

O fato de a hipótese da Percepção de Cocriação de Valor ter sido suportada para a amostra do Brasil e para a amostra de Portugal indicou que, assim como nas amostras do CouchSurfing, a avaliação do consumidor sobre a cocriação de valor vivenciada no serviço é importante para os utilizadores do Airbnb. O fato de a Perspectiva Anti-indústria ter sido suportada para ambas as amostras do Airbnb corrobora com a ideia que Lamberton e Rose (2012) apontaram de que as plataformas de consumo colaborativo podem proporcionar, em alguma medida, os ganhos psicológicos derivados de uma decisão que nega o apoio ao mercado tradicional. 
Já as hipóteses de que a Expectativa de Esforço, o Grau de Identificação entre Pares e a Influência Social têm relação direta com a Propensão de Uso não foram suportadas em nenhuma das amostras. Também não foi suportada a hipótese de que o Grau de Identificação entre Pares tem relação com a Confiança em nenhuma das duas amostras de Portugal e do Brasil do Airbnb.

Uma das diferenças nas amostras do Airbnb foi que a hipótese de que as Condições Facilitadoras têm relação direta com a Propensão de Uso foi suportada apenas para o público de Portugal e não para o público do Brasil. Outra diferença foi que a relação entre a Confiança e a Propensão ao Uso foi confirmada apenas para o público do Brasil e não foi suportada na amostra de Portugal.

\section{Considerações finais}

Esse estudo teve como objetivo principal propor um modelo teórico para verificar os fatores que contribuem para a propensão de uso de plataformas de economia do compartilhamento no âmbito do turismo. As recomendações gerenciais para organizações como o Airbnb, após o desenvolvimento deste trabalho, envolvem: encorajar a construção de um senso de comunidade, aumentar o desempenho e o valor utilitário do serviço, enfatizar os benefícios econômicos e enfatizar as motivações anti-indústria. O encorajamento de um senso de comunidade no Airbnb pode aumentar a confiança e a lealdade no serviço. Os resultados do presente estudo indicaram que a expectativa de experiências culturais compartilhadas representou um fator importante para a motivação de consumo do Airbnb. Mas, embora os resultados do estudo indiquem a receptividade dos consumidores aos aspectos de socialização com os anfitriões, outro importante objetivo de consumo deles é o serviço que está a ser oferecido. Isso pode ser comprovado com o resultado de que a Expectativa de Desempenho foi um preditor para a Intenção de Uso do Airbnb em ambas as amostras. Portanto, é importante priorizar a eficiência da prática e melhorar o valor utilitário que os consumidores recebem.

Notou-se como resultados que a Economia de Custos foi um fator motivador relevante para a Intenção de Uso do Airbnb. Os consumidores buscam, dessa forma, o acesso a um serviço da maneira mais eficiente e com melhor custo possível. Neste contexto, os clientes calculam o que recebem e o objetivo é ganhar mais utilidade em satisfazer suas necessidades. Por isso, é eficiente que as empresas como o Airbnb gastem seus recursos contribuindo para sua eficiência e os valores que os consumidores recebem do serviço. Podem concentrar-se no que os consumidores gostariam para alcançar e promover a inovação em serviços. Os gestores deveriam distringuir suas ofertas daquelas dos modelos de negócio tradicionais. As comunicações de marketing devem ser guiadas para mostrar que o consumo colaborativo fornece uma alternativa às indústrias tradicionais.

O presente trabalho também pode trazer uma contribuição gerencial não apenas para as organizações da economia compartilhada, mas também para as empresas tradicionais do campo do Turismo. Afinal, uma questão para o gestor da área de Hotelaria e Turismo é: o que é possível aprender com as organizações da economia compartilhada para aprimorar os 
serviços hoteleiros e turísticos? As conclusões deste trabalho podem ser úteis para estimular os gestores de empresas tradicionais a buscarem parcerias na economia compartilhada.

Este estudo apresenta como limitação a impossibilidade de generalização dos resultados em função do tipo de amostragem utilizado (não probabilística). Porém, ele pode ser tomado como referência e ser replicado, com alterações nas escalas, para estudar o comportamento do consumidor em outras plataformas de economia compartilhada de turismo como BeLocal Exchange, Worldpackers, Diáspora Black, entre outras.

Como o presente trabalho esteve voltado para entender a perspectiva do hóspede/consumidor de economia compartilhada no turismo, sugere-se que sejam realizados estudos futuros voltados também para entender a perspectiva do anfitrião. Outra sugestão é o desenvolvimento de estudos voltados especificamente para os fatores restritivos de consumo e os problemas/reclamações dos consumidores das plataformas de economia compartilhada de turismo. Trabalhos nesta diretriz são fundamentais para o melhoramento dos serviços e para indicar problemas a serem evitados nas experiências.

\section{Referências}

Algesheimer, R., Dholakia, M. U. \& Herrmann, A.v (2005). The social influence of brand community: Evidence from European car clubs. Journal of Marketing, 69, 19-34. doi: 10.1509/jmkg.69.3.19.66363

Bagozzi, R. P. \& Dholakia, U. M.v (2002). Intentional social action in virtual communities. Journal of Interactive Marketing, 16(2), 2-21. doi: 10.1002/dir.10006

Bardhi, F. \& Eckhardt, G. M. (2012). Access-based consumption: The case of car sharing. Journal of Consumer Research, 39(4), 881-898. doi: 10.1086/666376

Bardin, L. (1977). Análise de conteúdo. Lisboa: Edições 70.

Baron, S., Patterson, A., Warnaby, G. \& Harris, K. (2010). Service-dominant logic: Marketing research implications and opportunities. Journal of Customer Behaviour, 9(3), 253-264. doi: $10.1362 / 147539210 \times 533179$

Belk, R. \& Sobh, R. (2007). Is sharing an alternative to private ownership? International Review of Business Research Papers, 3(5), 78-87.

Belk, R. (2010). Sharing. Journal of Consumer Research, 36(5), 715-734.

Belk, R. (2014). You are what you can access: Sharing and collaborative consumption online. Journal of Business Research, 67(8), 1595-1600. doi: 10.1016/j.jbusres.2013.10.001

Bonsón Ponte, E., Carvajal-Trujillo, E. \& Escobar-Rodríguez, T. (2015). Influence of trust and perceived value on the intention to purchase travel online: Integrating the effects of assurance on trust antecedents. Tourism Management, 47, 286-302. doi: 10.1016/j.tourman.2014.10.009

Botsman, R. \& Rogers, R. (2011). O que é meu é seu: Como o consumo colaborativo vai mudar o nosso mundo. Porto Alegre: Bookman.

Chang, A. (2012). Utaut and Utaut 2: A review and agenda for future research. Journal The WINNERS, 13(2), 106-114.

Ert, E., Fleischer, A. \& Magen, N. (2016). Trust and reputation in the sharing economy: The role of personal photos in Airbnb. Tourism Management, 55, 62-73. doi: 10.1016/j.tourman.2016.01.013 
Ferreira, M. A. A. (2017). Economia alternativa: Feiras e Airbnb na cidade do Porto (Dissertação de mestrado não publicado). Universidade do Porto, Porto.

Giglio, V. S., Pinochet, L. H. C., Lopes, E. L., \& Azevedo, M. C. de. (2017). Fatores antecedentes da aceitação de jogos eletrônicos: Uma replicação do modelo UTAUT2 em jovens usuários. Revista GEINTEC, 7(2), 3844-3858.

Groth, M. (2005). Customers as good soldiers: Examining citizenship behaviors in internet service deliveries. Journal of Management, 31, 7-27. doi: 10.1177/0149206304271375

Guttentag, D. (2015). Airbnb: Disruptive innovation and the rise of an informal tourism accommodation sector. Current Issues in Tourism, 18(12), 1192-1217. doi: 10.1080/13683500.2013.827159

Hair Jr., J. F., Anderson, R. E., Tatham, R. L. \& Black, W. C. (2009). Análise multivariada de dados. Porto Alegre: Bookman.

Hair, J. H., Black, W. C., Babin, B. J. \& Anderson, R. E. (2014a). Multivariate data analysis. Harlow: Pearson.

Hair, J. F., Hult, G. T. M., Ringle, C. M. \& Sarstedt, M. (2014b). A primer on partial least squares structural equation modeling (PLS-SEM). Thousand Oaks: Sage.

Hair Jr, J. F., Sarstedt, M., Ringle, C. M. \& Gudergan, S. P. (2017). Advanced issues in partial least squares structural equation modeling. SAGE Publications.

Habibi, M. R., Davidson, A. \& Laroche, M. (2017). What managers should know about the sharing economy. Business Horizons, 60(1), 113-121. doi: 10.1016/j.bushor.2016.09.007

Hamari, J., Sjöklint, M. \& Ukkonen, A. (2016). The sharing economy: Why people participate in collaborative consumption. Journal of the Association for Information Science and Technology, 67(9), 2047-2059. doi: 10.1002/asi.23552

Heo, Y. (2016). Sharing economy and prospects in tourism research. Annals of Tourism Research, 58, 166-170. doi: 10.1016/j.annals.2016.02.002

Indrawati, and Haryoto, Kusumoaji Sri (2015). The use of modified theory of acceptance and use of technology 2 to predict prospective users' intention in adopting TV Streaming. In: 5th International Conference on Computing and Informatics (ICOCI) 2015, 11-13 August 2015, Istanbul, Turkey.

Kunz, W. \& Seshadri, S. (2015). From virtual travelers to real friends: Relationship-building insights from an online travel community. Journal of Business Research, 68(9), 1822-1828. doi: 10.1016/j.jbusres.2015.01.009

Lamberton, C. P. \& Rose, R. (2012). When is ours better than mine? A framework for understanding and altering participation in consumer sharing systems. Journal of Marketing, 76(4), 109-125. doi: $10.2139 /$ ssrn.1939289

Liang, L. J., Choi, H. C. \& Joppe, M. (2018). Understanding repurchase intention of Airbnb consumers: Perceived authenticity, electronic word-of-mouth, and price sensitivity. Journal of Travel \& Tourism Marketing, 35(1), 73-89. doi: 10.1080/10548408.2016.1224750

Lusch, R. F. \& Vargo, S. L. (2014). Service-dominant logic: Premises, perspectives, possibilities. Cambridge University Press.

Möhlmann, M. (2015). Collaborative consumption: Determinants of satisfaction and the likelihood of using a sharing economy option again. Journal of Consumer Behaviour, 14(3), 193-207. doi: $10.1002 / c b .1512$

Moore, G. C., \& Benbasat, I. (1991). Development of an instrument to measure the perceptions of adopting an information technology innovation. Information systems research, 2(3), 192-222. 
Ozanne, L. K. \& Ballantine, P. W. (2010). Sharing as a form of anti-consumption? An examination of toy library users. Journal of Consumer Behaviour, 9(6), 485-498. doi: 10.1002/cb.334

Sacks, D. (2011). The sharing economy. Fast company, 155(1), 88-131. [Artigo em website]. Disponível em: https://www.fastcompany.com/1747551/sharing-economy

Salomão, K. (2017). Airbnb movimentou R\$ 2 bilhões no Brasil em 2016. EXAME. Disponível em https://exame.com/negocios/Airbnb-movimentou-r-2-bilhoes-no-brasil-em-2016/

Satama, S. (2014). Consumer Adoption of Access-Based Consumption Services - Case Airbnb. Helsinki: Published Marketing Master's thesis, Aalto University School of Business. Disponível em: aaltodoc.aalto.fi/handle/123456789/13723

Silveira, L. M., Petrini, M. \& Santos, A. C. M. Z. Dv. (2016). Economia compartilhada e consumo colaborativo: o que estamos pesquisando? Revista de Gestão, 23(4), 298-305.

Slade, E. L., Dwivedi, Y. K., Piercy, N. C. \& Williams, M. D. (2015). Modeling consumers' adoption intentions of remote mobile payments in the United Kingdom: Extending UTAUT with innovativeness, risk, and trust. Psychology \& Marketing, 32(8), 860-873. doi: 10.1002/mar.20823

Souza, C. A. P. \& Lemos, R.v (2016). Aspectos jurídicos da economia do compartilhamento: Função social e tutela da confiança. Revista de Direito da Cidade, 8(4), 1757-1777. doi: 10.12957/rdc.2016.25740

Tussyadiah, I. P. \& Pesonen, J. (2015). Impacts of peer-to-peer accommodation use on travel patterns. Journal of Travel Research, 55(8), 1022-1040. doi: 10.1177/0047287515608505

Tussyadiah, I. P. (2016). Factors of satisfaction and intention to use peer-to-peer accommodation. International Journal of Hospitality Management, 55, 70-80. doi: 10.1016/j.ijhm.2016.03.005

Vargo, S. L. \& Lusch, R. F. (2004). Evolving to a new dominant logic for marketing. Journal of Marketing, 68(1), 1-17. doi: 10.1509/jmkg.68.1.1.24036

Venkatesh, V., Morris, M. G., Davis, G. B. \& Davis, F. D. (2003). User acceptance of information technology: Toward a unified view. MIS Quarterly, 27(3), 425-478. doi: 10.2307/30036540

Venkatesh, V., Thong, J. Y. L. \& Xu, X. (2012). Consumer acceptance and use of information technology: Extending the unified theory of acceptance and use of technology. MIS Quarterly, 36(1), 157178. doi: $10.2307 / 41410412$

Vera, L. A. R. \& Gosling, M. S. (2017). Economia compartilhada no turismo: Uma discussão teórica sobre o consumo colaborativo e o compartilhamento. Revista Eletrônica de Estratégia \& Negócios, 10(1), 226-251.

Yi, Y. \& Gong, T. (2008). If employees "go the extra mile", do customers reciprocate with similar behavior? Psychology and Marketing, 25(10), 961-986. doi: 10.1002/mar.20248

Yi, Y. \& Gong, T. (2013). Customer value co-creation behaviour: Scale development and validation. Journal of Business Research, 66(9), 1279-1284. doi: 10.1016/j.busres.2020.02.026

Yi, Y., Nataraajan, R. \& Gong, T. (2011). Customer participation and citizenship behavioural influences on employee performance, satisfaction, commitment, and turnover intention. Journal of Business Research, 64(1), 87-95. doi: 10.1016/j.jbusres.2009.12.007

Yuan, S., Ma, W., Kanthawala, S. \& Peng, W. (2015). Keep using my health apps: Discover users' perception of health and fitness apps with the UTAUT2 model. Telemedicine and E-Health, 21(9), 735-741. doi: 10.1089/tmj.2014.0148

Wang, X., Yu, C., \& Wei, Y. (2012). Social media peer communication and impacts on purchase intentions: A consumer socialization framework. Journal of Interactive Marketing, 26(4), 198208. 
Luciana Alves Rodas Vera é professora adjunta da Escola de Administração da Universidade Federal da Bahia (UFBA). Doutora em Administração pela Universidade Federal de Minas Gerais (UFMG) e mestre em Administração pela Universidade Federal da Bahia (UFBA). Endereço institucional: Departamento: Administração, Escola de Administração da Universidade Federal da Bahia, Salvador - Bahia, 40110903, Brasil, luciana.rodas@ufba.br.

Marlusa de SeVilha Gosling é professora associada da Universidade Federal de Minas Gerais (UFMG). Doutora e mestre em Administração pela Universidade Federal de Minas Gerais (UFMG). Endereço institucional: Departamento: Administração, Universidade Federal de Minas Gerais, Belo Horizonte Minas Gerais, 31270-901, Brasil,mg.ufmg@gmail.com.

JoÃo Albino Silva é professor da Faculdade de Economia da Universidade do Algarve. Investigador sênior no Centro de Investigação em Turismo, Sustentabilidade e Bem-Estar (CinTurs). Doutor em Economia pela Universidade Técnica de Lisboa. Endereço institucional: Departamento: Faculdade de Economia, Universidade do Algarve, Faro, 8005-139, Portugal, jsilva@ualg.pt.

Submetido em 27 de janeiro de 2020

Aceite em 30 de abril de 2020 